\title{
A Review of Pyrethroid and Mitin Analysis in Environmental Matrices by Sample Extraction \& Preparation, ELISAs with a Unique Focus on GC/NICl-MS
}

\author{
Peter J Baugh* \\ Leader of Environmental and Food Analysis Special Interest Group, The British Mass Spectrometry Society, UK
}

\begin{abstract}
Since the 1980s, pyrethroids, such as permethrin and cyfluthrin, have replaced other more intransigent and unreliable pesticides/insecticides as proofing agents for a range of applications, for example, to protect fabrics against moth invasion and bed net materials for employment in African countries in prevention of invasive mosquito attack.

However, these pyrethroids do present a small health hazard and care has to be taken during the process of application and handling, particularly, where the quantities applied are considerably above the levels allowed in environments occupied by or adjacent to human habitation, water, flora and fauna.

A number of analytical techniques have been used to monitor these pesticides, including chromatography mass spectrometry and ELISAs. Correlation between these techniques has been successfully investigated by researchers in the 1990s in relation to determining the levels of these pyrethroids in water courses, flora, fauna and in bed net materials. Parallel techniques have been used to analyse for mitins in environmental samples but employing LC/ESI-MS-MS.

This concise review outlines the earlier work and provides a brief summary of some of the more recent studies in the application of techniques since to highlight the research work undertaken with a unique focus on the utilization of GC/ $\mathrm{NICl-MS} \mathrm{in} \mathrm{conjunction} \mathrm{with} \mathrm{ELISA} \mathrm{for} \mathrm{pyrethroid} \mathrm{analysis} \mathrm{in} \mathrm{environmental} \mathrm{samples} \mathrm{and} \mathrm{for} \mathrm{LC/ESI-MS-MS} \mathrm{for} \mathrm{mitins} \mathrm{in}$ water environments. Selected and representative figures and tables are featured in the papers described to highlight the results obtained.
\end{abstract}

\section{Keywords}

Pyrethroids, Mitins, GC/NICl-MS, LC/ESI-MS-MS, ELISA, Environmental matrix, Sample preparation, Quantification, Correlation

\section{Introduction}

\section{Pyrethroids}

The pyrethroids are recognized as a major class of synthetic organic insecticides. Since commercial production in 1976, this group of compounds has achieved world-wide use with widespread agricultural and health applications. Of the major classes, pyrethroids as a group are among the most potent as insecticides but have been considered to exhibit comparatively low toxicity to mammals.

The pyrethroids reviewed here are broad spectrum synthetic insecticides with a greater photostability, enhanced insecticidal activity and low mammalian toxicity. Their effectiveness against a wide range of insects at extremely low dosage and limited persistence in the environment stimulated interest for use in agriculture around the world. At the same time, many countries have conducted research on the residual effects of these compounds on the environment af- ter use. Contamination of fresh water ecosystems by pyrethroids occurs either due to the direct discharge of industrial and agricultural effluents or through the effluents of sewage works where it is accumulated by the surrounding biosphere. The concentrations that have been measured in the soil suggest that this may be a serious problem in the areas to which such effluent is discharged. In the UK, recommendations have

*Corresponding author: Peter J Baugh, Leader of Environmental and Food Analysis Special Interest Group, EFASIG, The British Mass Spectrometry Society, c/o 23, Priory Road Sale M33 2BU, UK

Accepted: July 11, 2019

Published online: July 13, 2019

Citation: Baugh PJ (2019) A Review of Pyrethroid and Mitin Analysis in Environmental Matrices by Sample Extraction \& Preparation, ELISAs with a Unique Focus on $\mathrm{GC} / \mathrm{NICl}-\mathrm{MS}$. Current Trends Anal Bioanal Chem 3(1):125-144 
Citation: Baugh PJ (2019) A Review of Pyrethroid and Mitin Analysis in Environmental Matrices by Sample Extraction \& Preparation, ELISAs with A Unique Focus on GC/NICl-MS. Current Trends Anal Bioanal Chem 3(1):125-144

been issued for the safe use of some pyrethroids. The Food and Agricultural Organisation and WHO have prescribed residue limits for some pyrethroids in the area of agricultural and livestock products [1-3]. Other references provide data on the environmental quality standards (EQS) for pyrethroids [4].

Pyrethroids were introduced to replace Eulan WA New (a complex mixture of polyamino diphenyls, PADs, and polychloro sulphonamides, PCSDs) as mothproofing agents, which was detected and monitored in water courses by the National Rivers Authority, NRA (now Environment Agency, EA) resulting from effluent streams. A prime example, of the application of environmental monitoring was in the carpet industry, for example, in the vicinity of the Meltham catchment, West Yorkshire, UK. As a result there was a need to monitor the pollution of streams and rivers in the vicinity as considerable migration occurred from the factory because of leaching from the fabric into wooden flooring into which pyrethroids had been adsorbed. The relative persistence of pyrethroids because of lower biodegradability also presented some difficulties. The monitoring required involved sampling stream water, sediment, flora and fauna.

Methods for analysis of pyrethroid insecticides in a variety of matrices have previously been presented and reviewed. Most of these analytical procedures in the early work used GC-ECD and employed a variety of clean-up stage, see for example Bolygo and Zakar [5]. Jenkins, et al. [6] have reported the development and validation of a universal HPLC method with an update of references.

The methods have been applied to analyse these insecticides in water, crops and vegetables. The current review provides an extension of this early work to emphasize how the methodology had advanced in the 1990s to 2000s, and since, to demonstrate the validity of the more recent research work, in the light of current circumstances.

\section{Mitins}

The pattern of mothproofing agents has changed since the 1970s. Dieldrin was shown to be highly toxic to mammals and very persistent in the environment and replaced by formulations based on substituted ureas, urons.

The term mothproofing described the treatment of wool or wool-based fabrics to prevent damage by larvae of a number of insect pests that are capable of digesting keratin. Sulcofuron and flucofuron, as examples, exert their toxic effect on the target organism by inhibiting the synthesis of the enzyme required to break down keratin. These agents bond to wool fibres in the same way as dyes and are added in the process of dyeing. Restrictions apply to the formulations and in addition to being toxic, these must be stable to the application conditions, resistant to washing and light and effective for prolonged periods of the textile. Mitin is the trade name for the agent, which was produced by Ciba Geigy (Basle, Switzerland) and was marketed in the UK under Mitin FF (80\% sulcofuron) and Mitin LP (7.6\% flucofuron).

Regulations designed to limit the pollution of surface waters were introduced in the UK in 1993. Contamination of freshwater eco-systems occurs directly owing to the dis- charge of industrial effluents or indirectly through the discharge from sewage treatment works. In tests on activated sludge it was found that mitins were strongly absorbed akin to their persistence in the environment. The environmental quality standards (EQS) for sulcofuron and flucofuron in fresh water required to support fish are 25.0 and $1.0 \mu \mathrm{g} \mathrm{I}^{-1}$, respectively $[7,8]$.

The work in this review also focuses on the use of liquid chromatography with negative ion electro spray ionization tandem mass spectrometry (LC/ESI-MS-MS) for the determination of sulcofuron and flucofuron and the development of LLE, and SPE techniques for the determination of the analytes in surface waters, employing trichlorocarbanilide as an internal standard. The methods were successfully applied to samples obtained from a contaminated ecosystem.

Tadeo in 2019 has reviewed the analysis of pesticides in food and environmental samples [9].

The structures of permethrin, cyfluthrin, cypermethrin, deltamethrin, and fenvalerate, are illustrated in Figure 1.

The following section describes the methodology used and the published results of studies undertaken in the period 1990 to 2003 by different researchers in the Departments of Chemistry and Biological Sciences at the University of Salford. In the last section, a summary of the advances in the application of these methodologies in the period 2003 to date is made. The full report of the project is contained in Mothproofing Agents and Water Course Management (1996) R \& D Project Record [10].

\section{Research Work at the University of Salford, UK}

\section{ELISA development}

Elisas were developed specifically for a selected group of pyrethroids (viz., permethrin, cyfluthrin) and mitins like sulcofuron and flucofuron.

pAbs: Polyclonal antisera were produced in rabbits against two different synthetic immunogens, one of which incorporated 3-phenoxybenzoic acid (PBA) while the other contained dichlorovinyl cyclopropane carboxylate (CPA) [11]. The immunogens were constructed such that the hapten was coupled to the carrier protein through a peptide bond to a six carbon spacing group (6-amino hexanoic acid, 6-AHA). Both the anti-PBA and anti-CPA antisera obtained were able to detect permethrin when used in an indirect competitive enzyme-linked immunosorbent assay (IC-ELISA) format (see Figure 2). The detection limits typically obtained with both antisera were $10 \mathrm{mg} \mathrm{l}^{-1}$ with $50 \%$ inhibition of antibody binding (ho) at $100 \mathrm{mg} \mathrm{l}^{-1}$. Cross-reactivity with the pyrethroids cyfluthrin, phenothrin and deltamethrin was observed for both antisera, the degree of which was related to the structural similarity of the compound to the immunizing hapten. Further development of the immunoassay for permethrin was examined through use of the anti-PBA antiserum. Assay performance was improved by negative immunoaffinity chromatography of the anti-PBA antiserum, in which antibodies directed against the six carbon spacing group were removed. 
<smiles>CC(C)C(C(=O)OCc1cccc(Oc2ccccc2)c1)c1ccc(Cl)cc1</smiles>

Fenvalerate<smiles>[R]C([R])=C1C(C)C1(C)C(=O)OC([R2])c1ccc([R3])c(Oc2ccccc2)c1</smiles>

Permethrin $\mathrm{R}_{1}=\mathrm{Cl}, \mathrm{R}_{2}=\mathrm{H}, \mathrm{R}_{3}=\mathrm{H}$

Cyfluthrin $\mathrm{R}_{1}=\mathrm{Cl}, \mathrm{R}_{2}=\mathrm{CN}, \mathrm{R}_{3}=\mathrm{F}$

Cypermethrin $\mathrm{R}_{1}=\mathrm{Cl}, \mathrm{R}_{2}=\mathrm{CN}, \mathrm{R}_{3}=\mathrm{H}$

Deltamethrin $\mathrm{R}_{1}=\mathrm{Br}, \mathrm{R}_{2}=\mathrm{CN}, \mathrm{R}_{3}=\mathrm{H}$

Figure 1: Chemical structures of the pyrethroids reviewed.

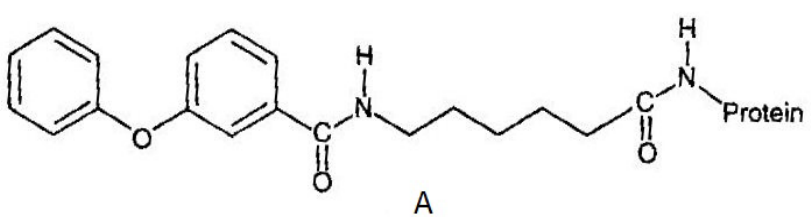

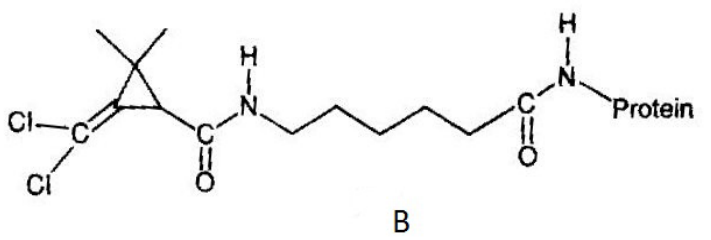<smiles>O=C(CCC(=O)OCc1cccc(Oc2ccccc2)c1)NC(=O)c1ccccc1</smiles>

Figure 2: Structures of hapten-carrier protein conjugates, containing A PBA with a six carbon spacing group; B) CPA with a six carbon spacing group; C) PBA-HS.

In conjunction with an avidin-biotin amplification step, typical detection limits were $1 \mathrm{mg} \mathrm{l}^{-1}$ with an $\mathrm{I}_{50}$ value of $15 \mathrm{mg} \mathrm{l}^{-1}$. Assay performance was considerably enhanced by use of a microtiter plate coating antigen which possessed a four carbon spacing group between the hapten and carrier protein. The hapten was also coupled to the spacing group through an ester bond. Typical detection limits for permethrin were 0.5 $\mu \mathrm{gl}^{-1}$, with an $\mathrm{I}_{50}$ value of $1 \mathrm{mg} \mathrm{l}^{-1}$ (Figure 3). This assay was also unaffected by the inclusion of methanol at concentrations of up to $10 \%$ by volume. The study indicated the potential use- fulness of antibodies raised against compounds which mimic moieties present within larger hapten molecules (anti-hapten mimic antibodies), particularly where the target analyte is not amenable to direct conjugation to a carrier protein.

mAbs: Monoclonal murine anti-pesticide antibodies were produced by in vitro immunisation (IVI) of cultured splenocytes with the pesticides sulcofuron and flucofuron [12]. The majority of both anti-flucofuron and anti-sulcofuron antibodies obtained were of the IgM isotype, rather than IgG. 


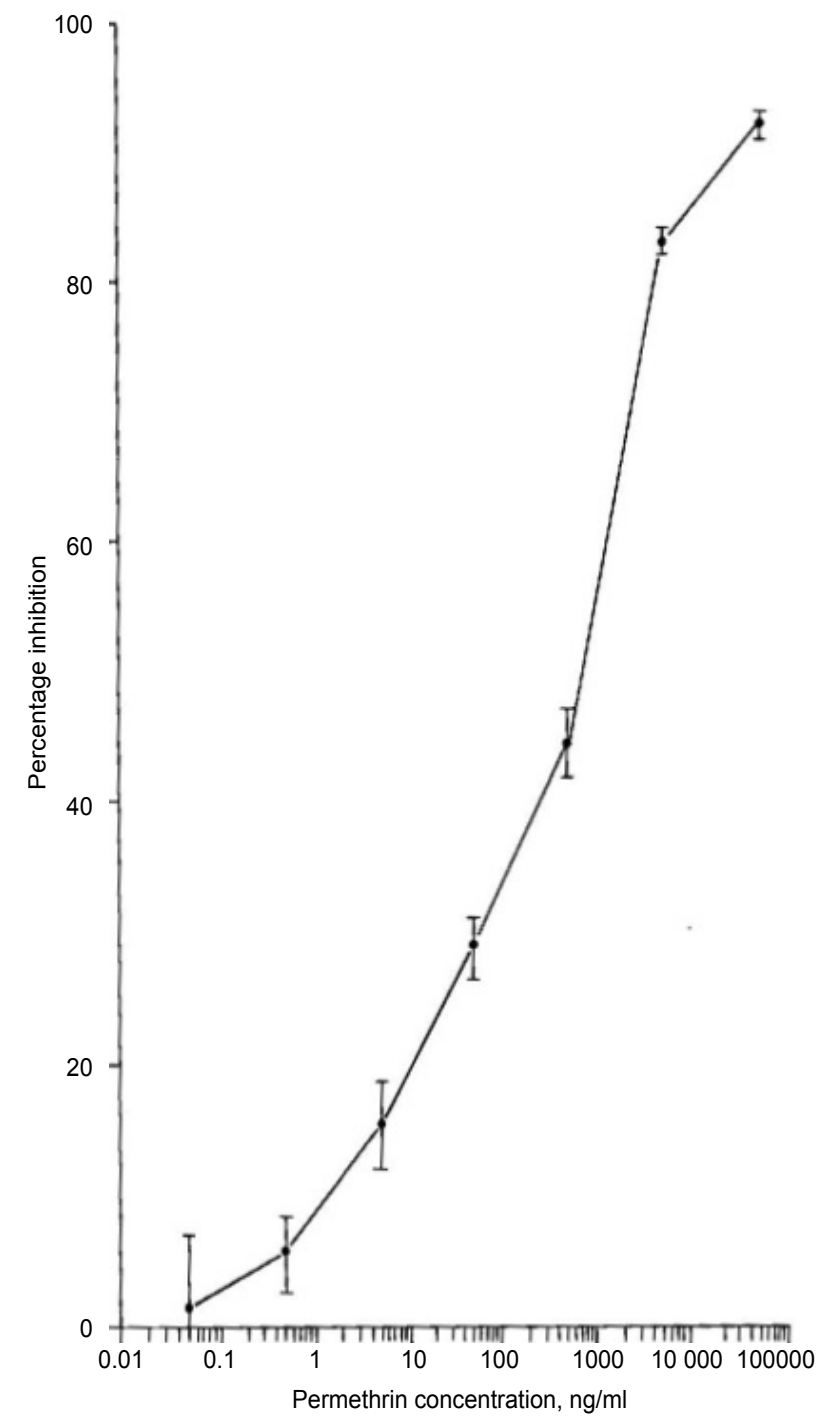

Figure 3: Representative IC-ELISA of permethrin with PBA-HSBSA as plate coating antigen. Mean percentage inhibitions and confidence limits (bar) derived from six observations.

When used in an indirect enzyme-linked immunosorbent assay (ELISA), the antibodies bound to plate coating antigens which incorporated haptens that mimicked moieties present within the immunising pesticide. The antibodies exhibited a high degree of specificity, with the degree of cross-reactivity related to the structural similarity between the hapten present in the plate coating antigen and the moieties present within the immunising pesticide. These results indicated that antibodies specific to both sulcofuron and flucofuron had been produced by IVI. Figures 4 and Figure 5 illustrate the IC elisa response vs concentration for flucofuron and sulcofuron, respectively Synthesis of both hapten analogues and immunogens as required for methods based on in vivo immunisation was avoided, whilst antibody production was also comparatively more rapid than traditional methods and minimised animal discomfort.

Gas chromatography/Mass spectrometry analysis in negative ion chemical ionization mode (GC)

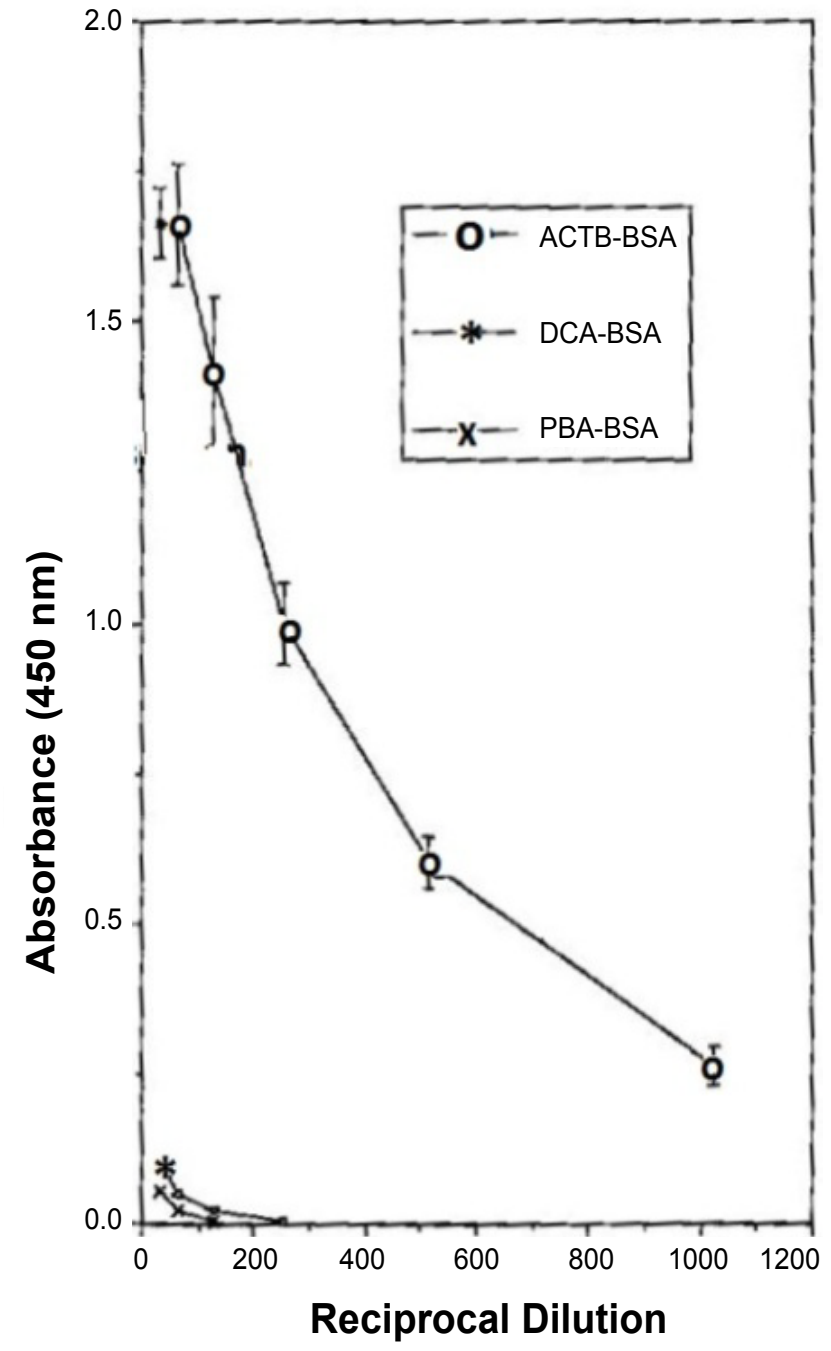

Figure 4: Binding of monoclonal antiflucofuron (F2A8/1/A4-B3) to hapten-BSA conjugates. Values presented are means of six observations \pm SD

\section{$\mathrm{NICl}-\mathrm{MS}$ ): Formation of negative ions as diagnos- tic fragments}

GC/MS analysis in $\mathrm{NICl}$ mode was used for the analysis of pyrethroids because the negative ion observed is specific to the target analyte of interest and more so than for electron Ionisation (EI), which produces the considerably less diagnostic phenoxybenzene carboxylate positive ion fragment. Also cis and trans isomer negative ion fragments and isotope ratio profiles assist in positive identification of the target analytes. Quantisation of the ions is conducted using these isomer and isotopic ratio profiles. Furthermore, the sensitivity is enhanced over EI-MS, which assists in complying with detection limits as required by legislation. The general reactions for the formation of negative ions are as follows:

Reagent gas reactions $\mathrm{CH}_{4}+\mathrm{e}^{-} ; \mathrm{CH}_{4}^{+} 2 \mathrm{e}^{-} ; \mathrm{CH}_{4}^{+}+\mathrm{CH}_{4}^{-->\mathrm{CH}_{3}}$ $+\mathrm{CH}_{5}{ }^{+} \mathrm{PICl}$ mode

Pyrethroid target ROR' $+\mathrm{e}^{-} \rightarrow\left[\mathrm{ROR}^{\prime}\right]^{--} \rightarrow \mathrm{R}+\left[\mathrm{OR}^{\prime}\right]^{--} \mathrm{NICl}$ mode, dissociative electron capture

Where $\left[O R^{\prime}\right]^{--}$is the diagnostic negative ion fragment for 
Citation: Baugh PJ (2019) A Review of Pyrethroid and Mitin Analysis in Environmental Matrices by Sample Extraction \& Preparation, ELISAs with A Unique Focus on GC/NICl-MS. Current Trends Anal Bioanal Chem 3(1):125-144

the target pyrethroid for which the structures are of the form, $R^{\prime \prime}$ dimethyl cyclopropane carboxylate anion, $\mathrm{m} / \mathrm{z} 207$, 209 , where $R^{\prime \prime}$ is dichloro vinyl end group for permethrin, cypermethrin and cyfluthrin pyrethroids being considered. Deltamethrin, undergoes dissociative electron capture to produce the isotopic profile for $\mathrm{Br}^{-}[13,14]$ although $\mathrm{m} / \mathrm{z} 137$ [15] observed can also be utilized in analysis (dissociation energy dependent). $\lambda$-Cyhalothrin yields $\mathrm{m} / \mathrm{z} 241,243$ [15] and fenvalerate, $\mathrm{m} / \mathrm{z} 211,213$ [13-15]. Figures 6, Figure 7 and Figure 8 show the mass spectral and chromatographic profiles for the pyrethroids investigated (Table 1).

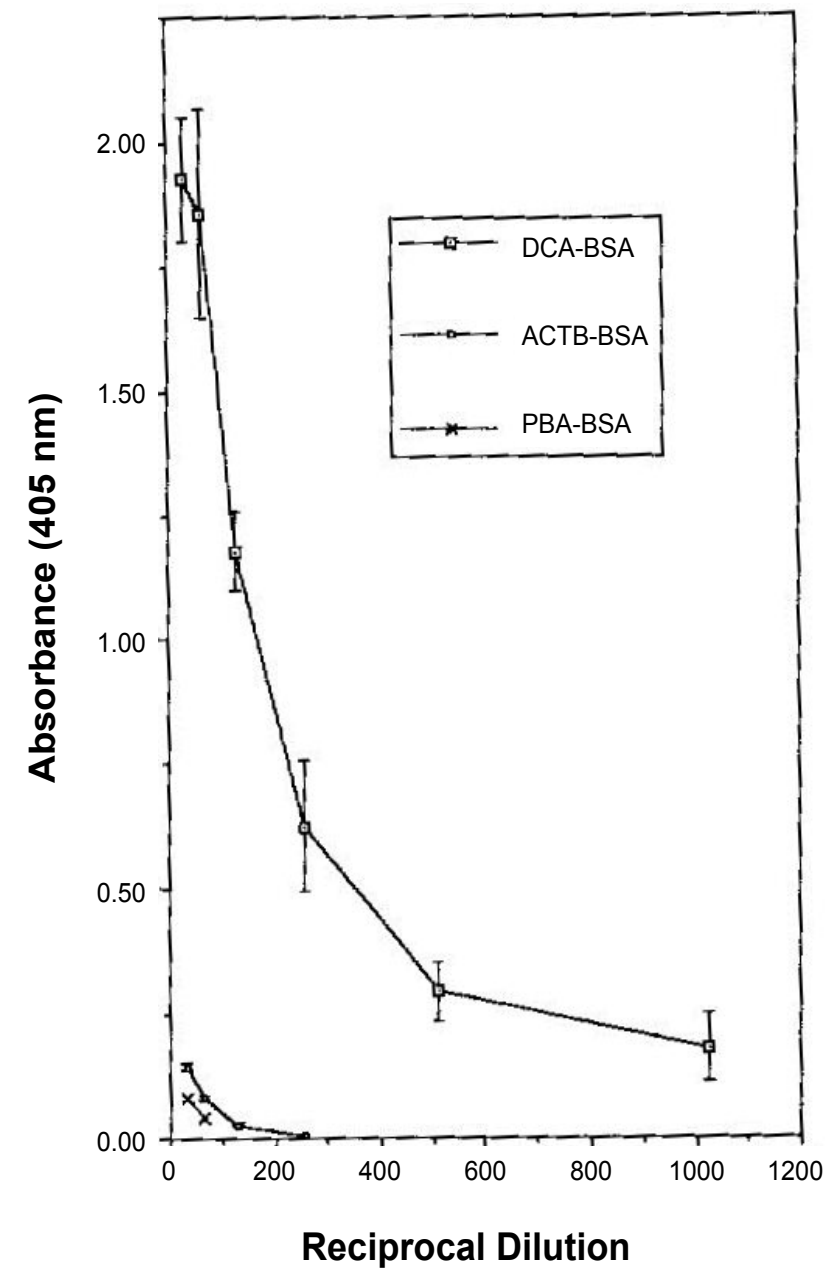

Figure 5: Same legend for binding of monoclonal sulcofuron (S2B5/1/G3) to hapten-BSA conjugates.

\section{ELISA and GC/MS correlation}

Comparative studies were conducted to correlate Elisa and GC/MS data to determine the effectiveness of Elisa for permethrin analysis at concentrations above the maximum residue level (MRL). The following paragraphs describe the development of comparative analytical for permethrin [16]
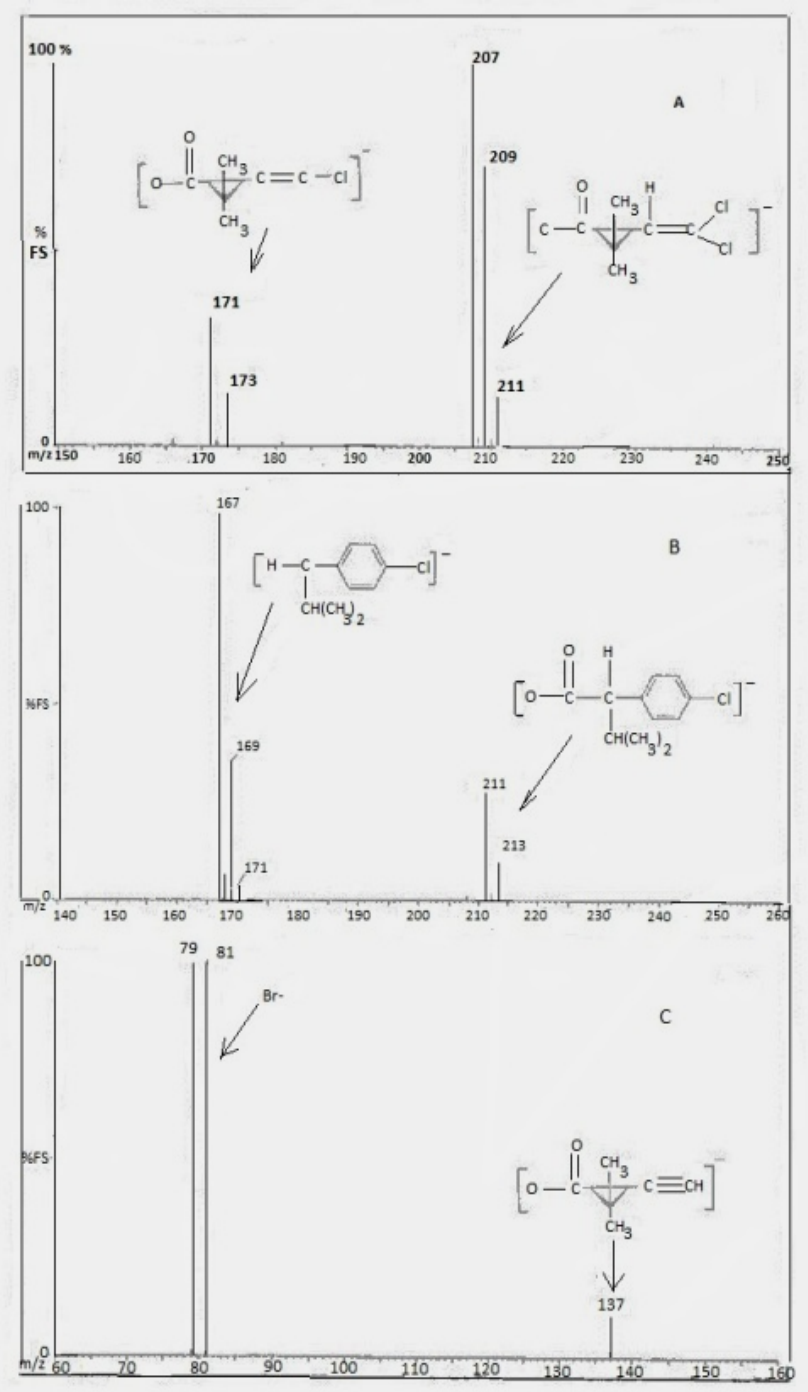

Figure 6: NICl-MS mass spectra for A) Permethrin, Cyfluthrin and Cypermethrin; B) Fenvalerate; C) Deltamethrin illustrating the diagnostic negative ion fragments resulting from dissociative electron capture.

Table 1: Characteristic negative mass ions for the pyrethroids reviewed and selected for quantification.

\begin{tabular}{|l|l|l|}
\hline Compound & Characteristic lons, $\mathbf{m} / \mathbf{z}$ & Quantification Ion \\
\hline Permethrin & $171,173,207,209,211$ & 207 \\
\hline Cyfluthrin & $171,173,207,209,211$ & 207 \\
\hline Cypermethrin & $171,173,207,209,211$ & 207 \\
\hline Deltamethrin & $79,81,137$ & 79 \\
\hline Fenvalerate & $167,169,211,213$ & 167 \\
\hline Mirex, Standard & $366,368,370,402,404,406$ & 368 or 404 \\
\hline DCBP, Standard & $496,498,500$ & 498 \\
\hline
\end{tabular}


Citation: Baugh PJ (2019) A Review of Pyrethroid and Mitin Analysis in Environmental Matrices by Sample Extraction \& Preparation, ELISAs with A Unique Focus on GC/NICl-MS. Current Trends Anal Bioanal Chem 3(1):125-144

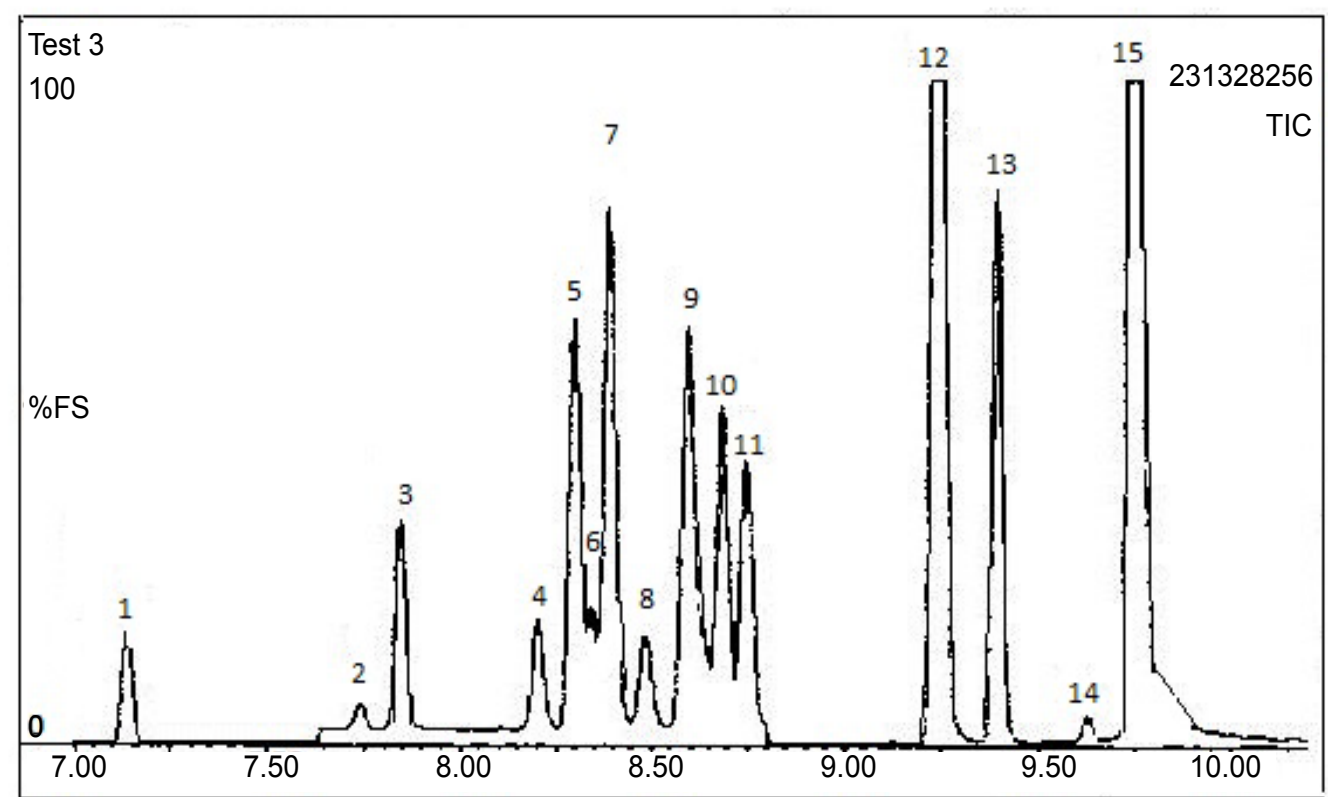

Figure 7: Total ion chromatogram (TIC) for pyrethroids and internal and volumetric standards: 1 mirex, 2 and 3 cis/trans permethrin, 4 , 5, 6, 7 cyfluthrin $(R+S), 8,9$, and 10 cypermethrin; 11, decachlorobiphenyl (DCBP); 12 and 13, Fenvalerate; 14 and 15, deltamethrin.
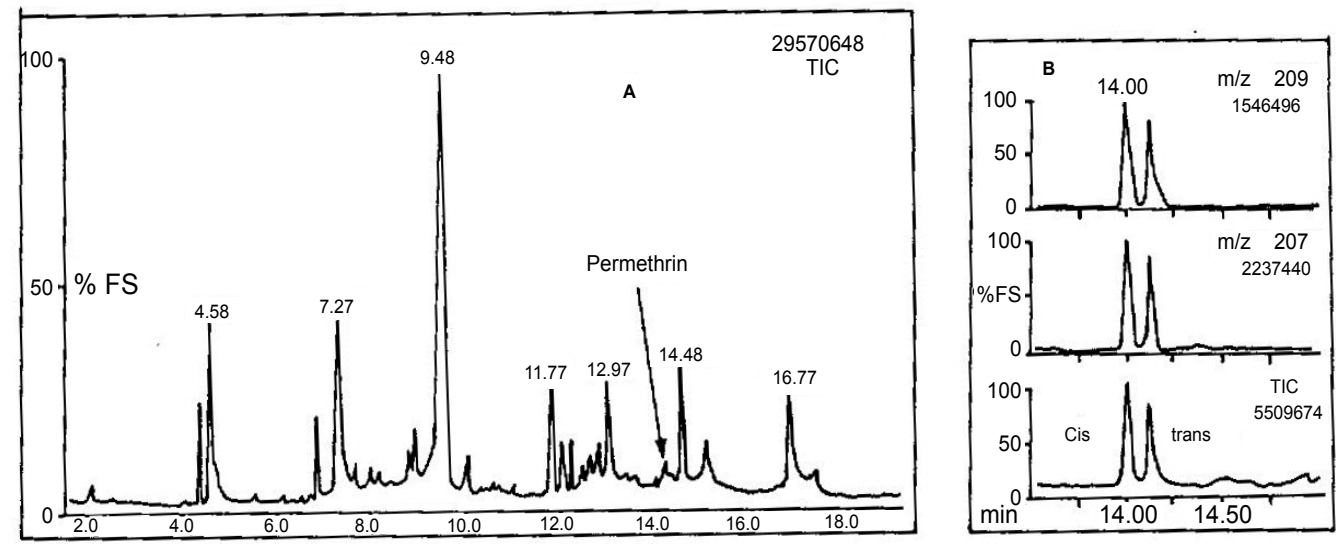

Figure 8: $\mathrm{GC} / \mathrm{NICl}-\mathrm{MS}$ Total ion chromatogram A) And mass chromatograms and TIC; $\mathrm{B}$ ) For cis and trans permethrin, identified by negative ions at $\mathrm{m} / \mathrm{z} 207$ and 209.

and an application to fish sampled from headwater stream [17].

The synthetic pyrethroid permethrin has widespread use in agriculture and, as a result, is found in a variety of matrices. Chemical methods based on GC/MS operated in $\mathrm{NICl}$ mode (GC-NICl/MS) have been developed [16] Sample extraction techniques, such as, ultrasonication and steam distillation have also been examined. Significant improvements have been made, compared with traditional methods, in both sample extraction time and detection level for a range of matrices. Enzyme-linked immunosorbent assay (ELISA) methods have also been developed for permethrin (refer to Figure 3, section 2.1.1, for the IC-ELISA calibration curve for permethrin). This study addressed the comparison of ELISA and chemical assays for permethrin in a variety of both environmental and laboratory-spiked samples. The sensitivities, specificities and potential applications of these methods were discussed. Figure 9 illustrates the high quality data for the calibration of permethrin in the concentration range, 0 to $80 \mu \mathrm{g} \mathrm{I}^{-1}$, using $\mathrm{GC} / \mathrm{NICl}-\mathrm{MS}$. Figure 9 illustrates the location of the sampling sites and Tables 2, Table 3 and Table 4 summarise the data correlation between $\mathrm{GC} / \mathrm{NICl}-\mathrm{MS}$ and ELISA for permethrin in water, sediment and white muscle from fish.

Brown trout (Salmo trutta) were captured from a headwater stream contaminated with moth-proofing agents [17] (Figure 10 and Figure 11). Synthetic pyrethroid residues within the tissues were obtained by ultrasonic extraction and examined by $\mathrm{GC} / \mathrm{NICl}-\mathrm{MS}$. Both permethrin and cyfluthrin had been bioaccumulated by the fish and the mean concentrations \pm standard deviation recorded were $2046 \pm 203 \mu \mathrm{g}$ $\mathrm{kg}^{-1}$ and $25.4 \pm 46.9 \mu \mathrm{g} \mathrm{kg}^{-1}$ respectively. The concentrations of these pyrethroids are the highest recorded for freshwater 


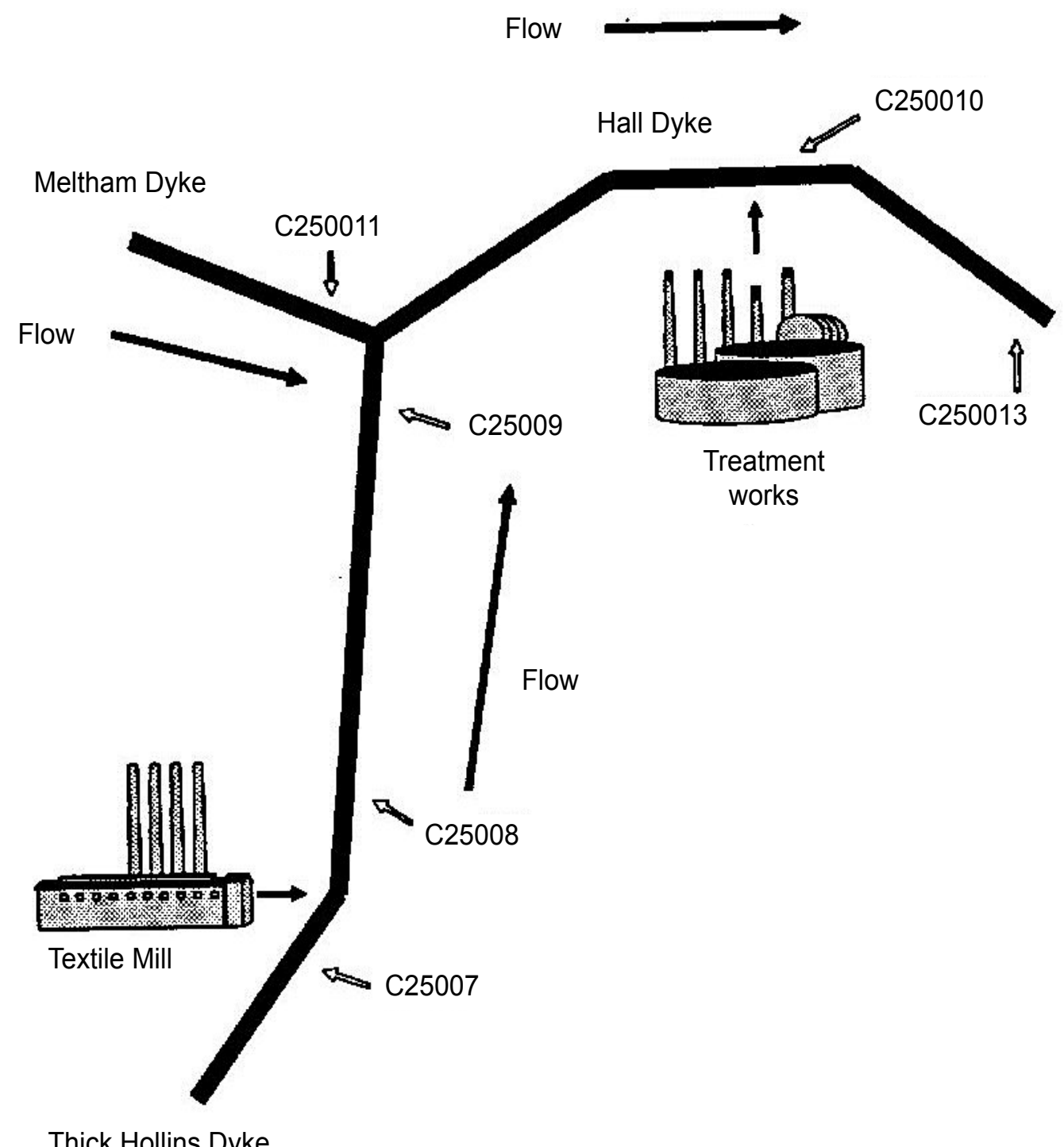

Figure 9: Location of sample sites in the Meltham Catchment, West Yokshire, UK.

Table 2: Data correlation between GC/NICI-MS and ELISA for permethrin in water samples from the River Calder catchment (West Yorkshire, UK).

\begin{tabular}{|l|l|l|}
\hline Site & $\begin{array}{l}\text { GC/NICI-MS } \\
\left(\mu \mathrm{g} \mathrm{I}^{-1}\right)\end{array}$ & $\begin{array}{l}\text { ELISA } \\
\left(\mu \mathrm{g} \mathrm{I}^{-1}\right)\end{array}$ \\
\hline C25007 & $\mathrm{ND}^{\mathrm{a}}$ & ND \\
\hline $\mathrm{C} 25008$ & 0.047 & ND \\
\hline C25009 & 0.025 & ND \\
\hline C250010 & 0.607 & 0.28 \\
\hline C250011 & 0.035 & ND \\
\hline C250013 & 0.289 & 0.13 \\
\hline
\end{tabular}

${ }^{a}$ Not detected.

fish captured from a natural ecosystem. At the time of sampling, permethrin could be detected within the stream water $\left(0.034 \mathrm{\mu g} \mathrm{I}^{-1}\right)$ while cyfluthrin could not. A mean relative bioconcentration factor of approximately 60,000 was derived for
Table 3: Data correlation between GC/NICl-MS and ELISA for permethrin in sediment from the River calder catchment, West yorkshire, UK.

\begin{tabular}{|l|l|l|}
\hline Site & $\begin{array}{l}\text { GC/NICI-MS } \\
\left(\mu \mathbf{~ k g}^{-1}\right)\end{array}$ & $\begin{array}{l}\text { ELISA } \\
\left(\mu \mathbf{~ k g}^{-1}\right)\end{array}$ \\
\hline C25007 & 3.0 & ND $^{\mathrm{a}}$ \\
\hline C25008 & 878 & 750 \\
\hline C25009 & 134.4 & 85 \\
\hline C250010 & 2936 & 3100 \\
\hline C250011 & 31.6 & 12.5 \\
\hline C250013 & 928 & 820 \\
\hline
\end{tabular}

${ }^{a}$ Not detected.

the brown trout which was also greater than any previously determined for freshwater fish. The fish tissue extracts were also analyzed through use of an ELISA for permethrin. The ELISA reported consistently lower concentrations than those 
Citation: Baugh PJ (2019) A Review of Pyrethroid and Mitin Analysis in Environmental Matrices by Sample Extraction \& Preparation, ELISAs with A Unique Focus on GC/NICl-MS. Current Trends Anal Bioanal Chem 3(1):125-144

Table 4: Data correlation between GC/NICI-MS and ELISA for permethrin in spiked fish white muscle (gadus morhua) from the River Calder catchment, West Yorkshire, UK.

\begin{tabular}{|l|l|}
\hline $\mathbf{G C} / \mathrm{NICI}-\mathrm{MS}\left(\boldsymbol{\mu \mathbf { ~ } ^ { - 1 }}\right)$ & ELISA $\left(\boldsymbol{\mu} \mathbf{~ k g}^{-\mathbf{1}}\right)$ \\
\hline 0.0 & 0.0 \\
\hline 2.6 & $\mathrm{ND}^{\mathrm{a}}$ \\
\hline 19.2 & $\mathrm{ND}$ \\
\hline 26.0 & 17.5 \\
\hline 31.6 & 150 \\
\hline 201.2 & 820 \\
\hline
\end{tabular}

NDa None detected.

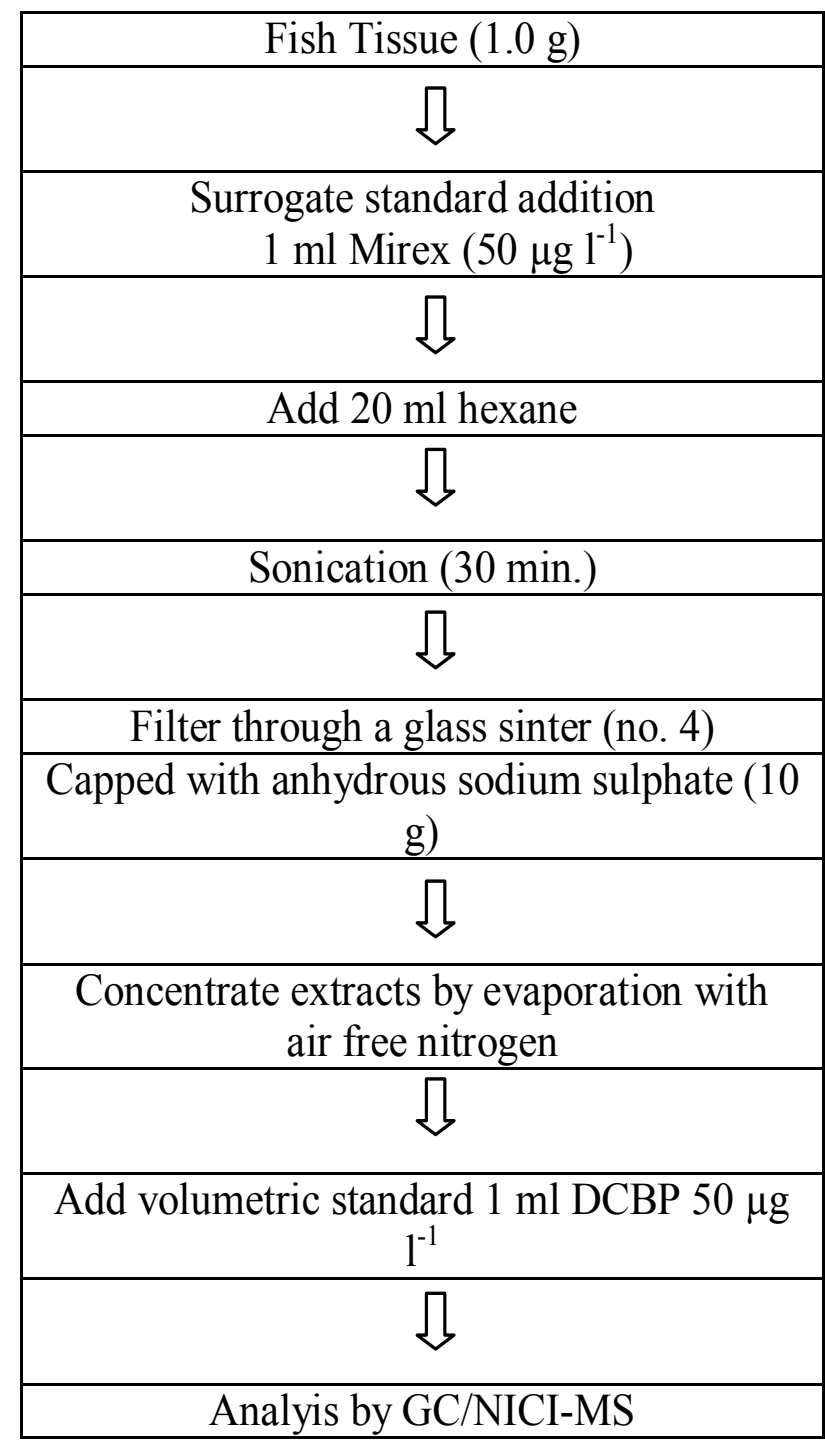

Figure 10: Scheme for the preparation of brown trout (Salmo trutta) tissues for analysis by GC/NICl-MS.

obtained by GC/NCl-MS. This was attributed to analyte losses during preparation of the sample extracts in a form suitable for incorporation into the ELISA. The concentrations obtained by ELISA were significantly correlated with those obtained by GC/NICI-MS $\left(R^{2}=0.985, n=5\right)$. Overall, the ELISA appeared
Table 5: Comparison of permethrin concentrations in brown trout (Salmo trutta) obtained by GC/NICl-MS and ELISA.

\begin{tabular}{|l|l|l|}
\hline Sample & $\begin{array}{l}\mathbf{G C} / \mathbf{N I C I}-\mathbf{M S} \\
\left(\boldsymbol{\mu \mathbf { g ~ } ^ { - 1 }}\right)\end{array}$ & $\begin{array}{l}\text { ELISA } \\
\left(\boldsymbol{\mu g} \mathbf{~ k g}^{-1}\right)\end{array}$ \\
\hline Fish 1 & 3900 & 3000 \\
\hline Fish 2 & 2290 & 1600 \\
\hline Fish 3 & 1420 & 900 \\
\hline Fish 4 & 1950 & 1100 \\
\hline Fish 5 & 670 & 1100 \\
\hline
\end{tabular}

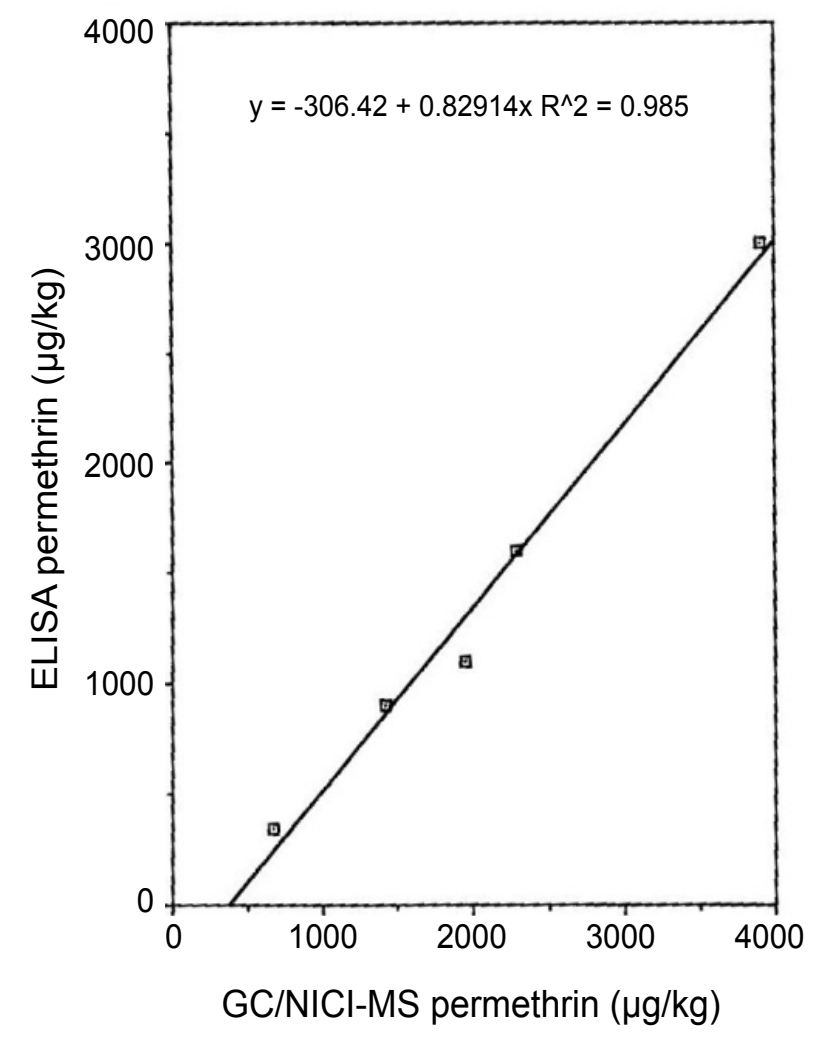

Figure 11: Correlation between permethrin concentration sin brown trout (Salmo trutta) obtained by GC/NICl-MS and ELISA.

to be suitable for the detection of permethrin in fish when present at concentrations in excess of the MRL suggested for many foods by the Commission of the European Economic Community (Table 5).

Unpublished results presented as posters at meetings $[18,19]$ focused on the correlation between Elisa and GC/ $\mathrm{NICl}-\mathrm{MS}$ for determining permethrin residues in mosquito net materials [20]. Approximate linearity in the correlation was observed for the concentrations determined.

\section{GC NICI-MS development and Applications}

Methods were developed for pyrethroids in environmental matrices. GC-NICl-MS with selected-ion monitoring (SIM) showed both high sensitivity and excellent specificity for permethrin and cyfluthrin [21].

The detection limit for both permethrin and cyfluthrin 


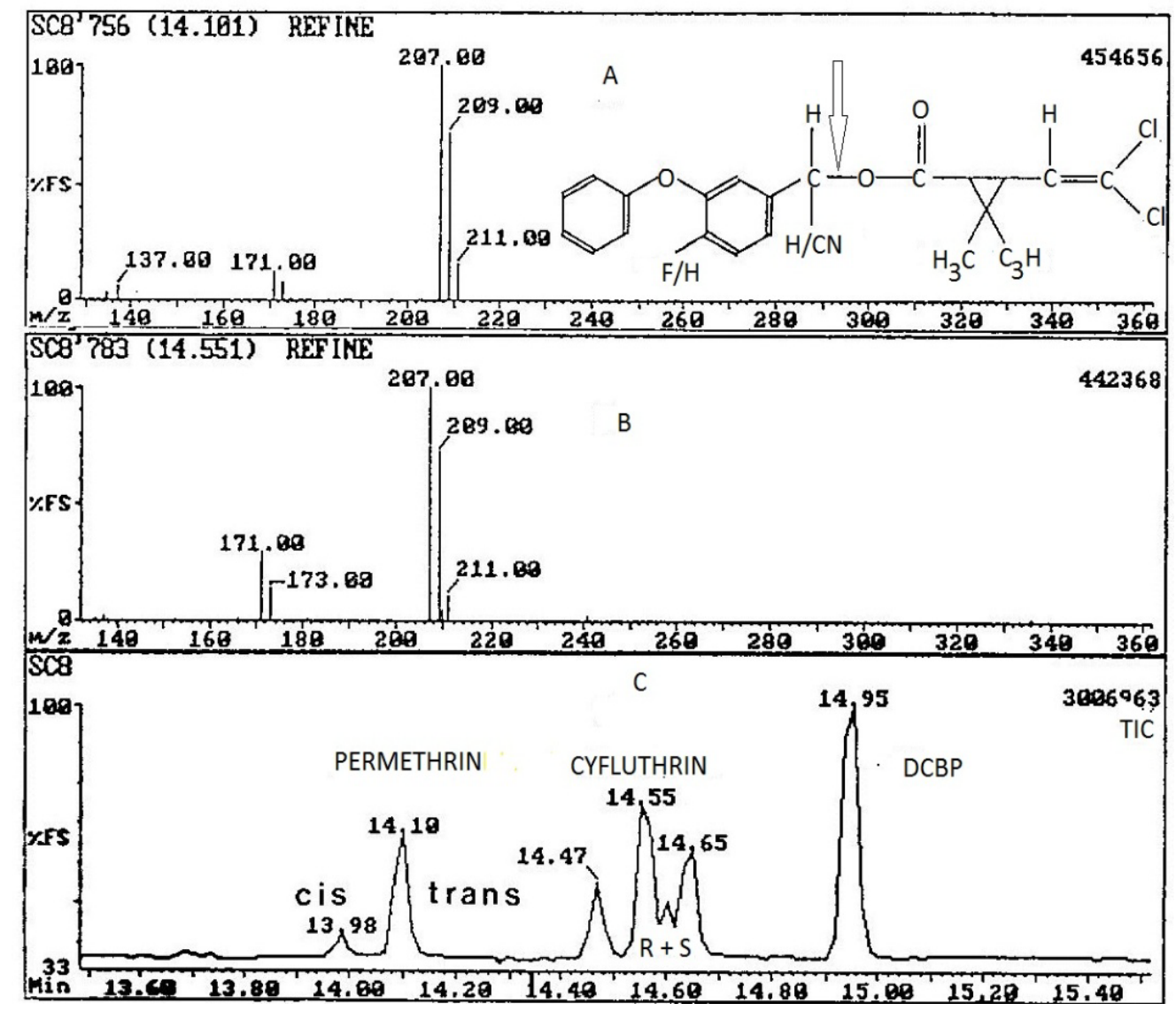

Figure 12: A/B) Negative ion chemical ionisation mass spectra and TIC; C) For permethrin and cyfluthrin analysed by GC/NICI-MS, dissociative electron capture occurs at the PBA - CPA bond link, see A.

Table 6: Percentage recoveries of permethrin and cyfluthrin from spiked water samples.

\begin{tabular}{|l|l|l|}
\hline $\begin{array}{l}\text { Concentration range } \\
\text { (ng } \mathbf{~ I}^{-1} \text { ) }\end{array}$ & $\begin{array}{l}\text { Permethrin } \\
\text { recovery (\%) }\end{array}$ & $\begin{array}{l}\text { Cyfluthrin } \\
\text { recovery (\%) }\end{array}$ \\
\hline $0.05-0.5$ & $115.5 \pm 7.3(6)$ & $97.0 \pm 10.4(7)$ \\
\hline $1.0-5.0$ & $98.4 \pm 13.1(5)$ & $98.4 \pm 21.6(5)$ \\
\hline $10-50$ & $104.1 \pm 16.5(6)$ & $99.5 \pm 6.6(6)$ \\
\hline $100-500$ & $101.5 \pm 17.5(6)$ & $101.2 \pm 14.0(5)$ \\
\hline
\end{tabular}

Table 7: Percentage recoveries of permethrin and cyfluthrin from spiked sediment samples.

\begin{tabular}{|l|l|l|}
\hline $\begin{array}{l}\text { Concentration range } \\
\left(\boldsymbol{\mu g} \mathbf{~ k g l}^{-1}\right)\end{array}$ & $\begin{array}{l}\text { Permethrin } \\
\text { recovery (\%) }\end{array}$ & $\begin{array}{l}\text { Cyfluthrin } \\
\text { recovery (\%) }\end{array}$ \\
\hline $0.005-0.5$ & $88.4 \pm 21.5(5)$ & $94.6 \pm 7.3(4)$ \\
\hline $0.01-0.5$ & $91.5 \pm 14.4(9)$ & $96.3 \pm 13.0(9)$ \\
\hline $1-5$ & $94.7 \pm 15.8(10)$ & $98.4 \pm 12.4(10)$ \\
\hline $10-200$ & $82.3 \pm 9.7(10)$ & $90.5 \pm 21.4(10)$ \\
\hline
\end{tabular}

was $50 \mathrm{fg}$, whilst a linear response was observed from $50 \mathrm{fg}$ to $80 \mathrm{pg}$. A sample extraction method using an ultrasonic bath was developed enabling simultaneous processing of multiple samples. Good percentage recoveries of both permethrin and cyfluthrin from spiked sediments were obtained (97.3
Table 8: Permethrin and cyfluthrin levels in water and sediment samples from the River Calder cartchment, West Yorkshire, UK.

\begin{tabular}{|l|l|l|l|l|}
\hline \multirow{3}{*}{ Site } & \multicolumn{2}{|l|}{ Water samples $\left(\mu \mathrm{g} \mathrm{I}^{-1}\right)$} & \multicolumn{2}{l|}{ Sediment samples $\left(\boldsymbol{\mu g} \mathbf{~ k g}^{-1}\right)$} \\
\cline { 2 - 5 } & Permethrin & Cyfluthrin & Permethrin & Cyfluthrin \\
\hline A & 0.020 & ND & 214.0 & ND \\
\hline B & 0.048 & ND & 335.0 & ND \\
\hline C & ND $^{\text {a }}$ & ND & ND & ND \\
\hline
\end{tabular}

$N D^{a}$ : None detected.

$\pm 4.8 \%$ and $93.9 \pm 5.3 \%$, respectively) and sample clean-up was avoided. These methods were also successfully applied to samples obtained from a contaminated ecosystem, the highest concentrations recorded in water and sediment samples were $0.048 \mu \mathrm{g} \mathrm{I}^{-1}$ and $335 \mu \mathrm{g} \mathrm{kg}^{-1}$, respectively. Figure 12 illustrates the $\mathrm{NICl}$ mass spectra and the TIC for cis/trans permethrin and $R$ \& $S$ isomers for cyfluthrin. Tables 6 and Table 7 summarise the recoveries for the two analytes from spiked water and sediment samples, respectively. Table 8 shows the data for permethrin and cyfluthrin levels in water and sediment samples from sites A B and C in the River Calder cartchment, West Yorkshire, UK.

A GC/MS method was developed for the simultaneous determination of five synthetic pyrethroid insecticides, namel, permethrin, cyfluthrin, cypermethrin, fenvalerate and deltamethrin, in soil, moss and fish tissue [13]. These pyrethroids 


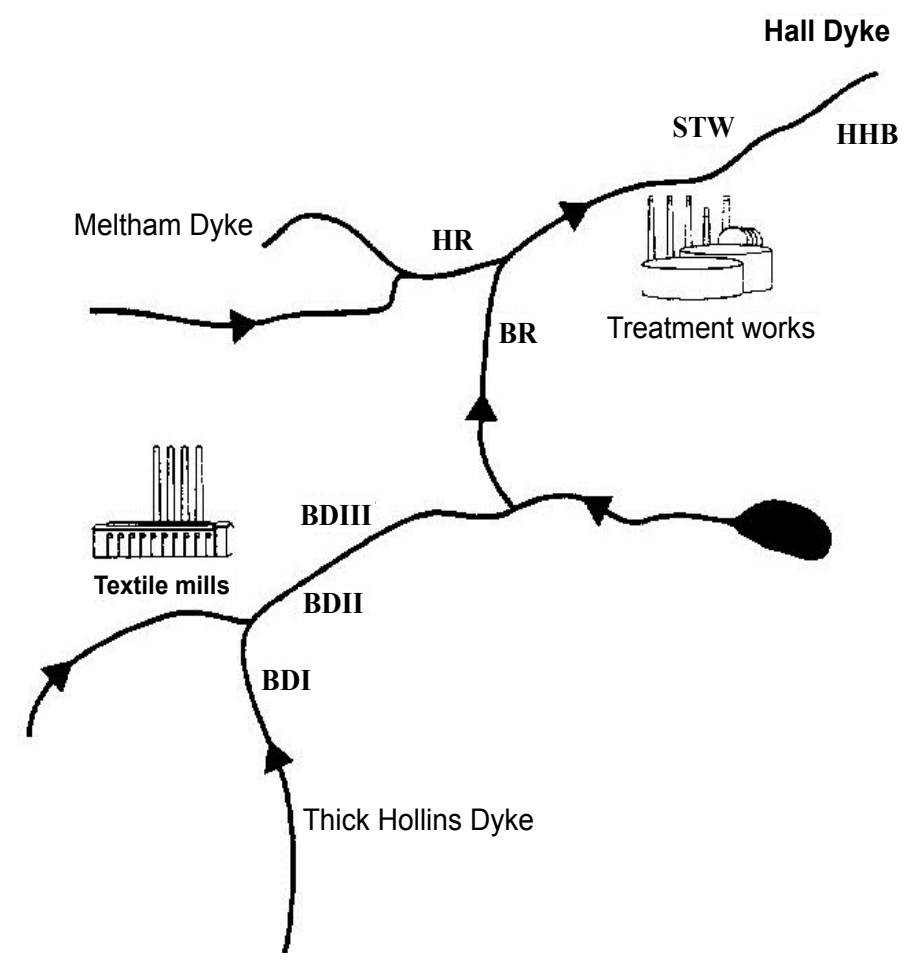

Figure 13: Location of sampling sites in the Meltham Catchment, West Yorkshire, UK.

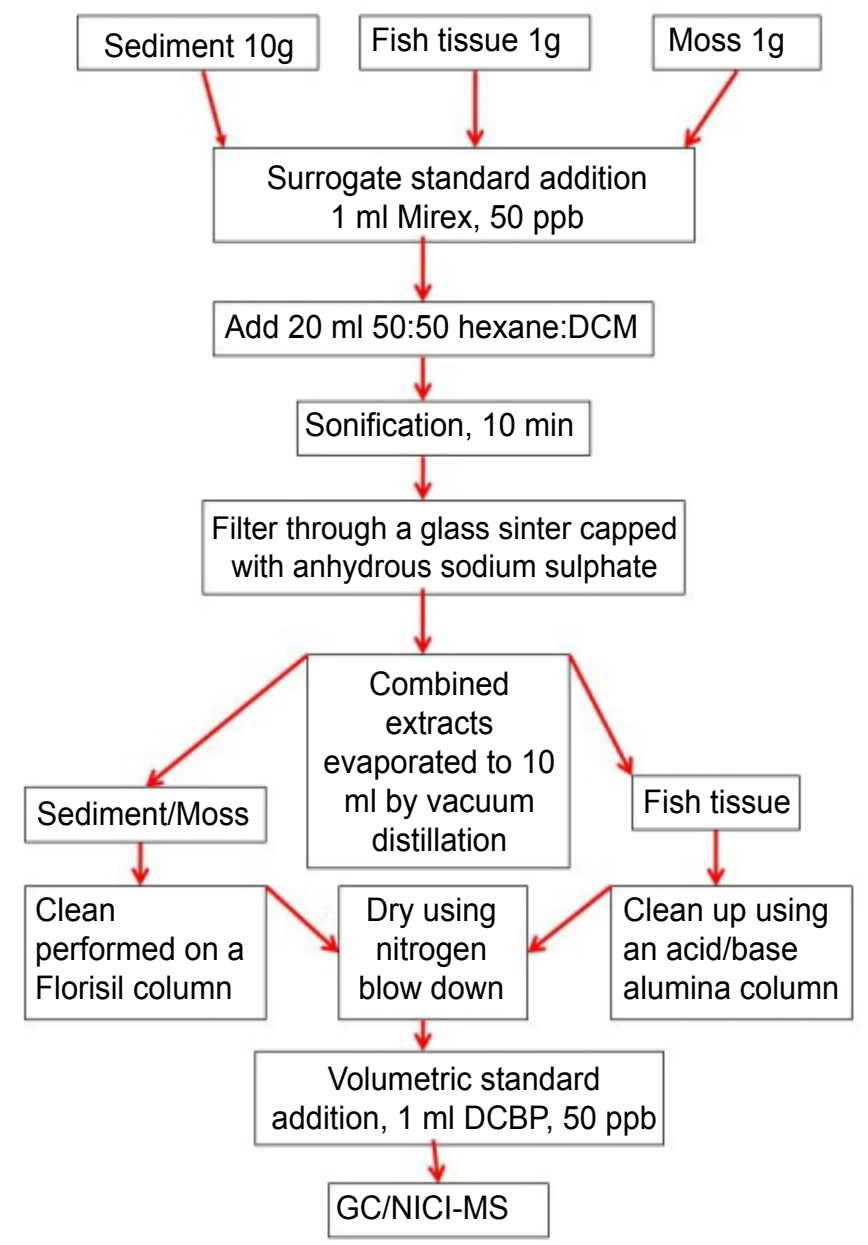

Figure 14: Scheme for the sample preparation and analysis of pyrethroids by GC/NICl-MS. 
Citation: Baugh PJ (2019) A Review of Pyrethroid and Mitin Analysis in Environmental Matrices by Sample Extraction \& Preparation, ELISAs with A Unique Focus on GC/NICl-MS. Current Trends Anal Bioanal Chem 3(1):125-144

Table 9: Recoveries of pyrethroids from soil at $10 \mathrm{ppb}$ fortification levels with three solvent systems.

\begin{tabular}{|l|l|l|l|}
\hline & \multicolumn{3}{|l|}{ Average recovery (\%) \pm S.D. } \\
\hline Compound & Hexane & Hexane: DCM & $\begin{array}{l}\text { Hexane: } \\
\text { Acetone }\end{array}$ \\
\hline Permethrin cis & $114.1 \pm 5.4$ & $113 \pm 2.4$ & $117.5 \pm 3.5$ \\
\hline Permethrin trans & $97.4 \pm 1.0$ & $101.9 \pm 2.4$ & $107.1 \pm 1.6$ \\
\hline Fenvalerate cis & $20.2 \pm 3.2$ & $99.1 \pm 3.5$ & $116.5 \pm 3.1$ \\
\hline Fenvalerate trans & $17.9 \pm 0.7$ & $100.3 \pm 2.8$ & $11.5 \pm 1.8$ \\
\hline Cyfluthrin & $15.7 \pm 2.7$ & $103.3 \pm 3.1$ & $117.1 \pm 0.8$ \\
\hline Cypermethrin & $17.8 \pm 2.3$ & $106.1 \pm 3.5$ & $114.5 \pm 3.7$ \\
\hline Deltamethrin & $18.78 \pm 4.3$ & $106.8 \pm 1.0$ & $119.44 \pm 1.8$ \\
\hline Mirex & $81.5 \pm 2.8$ & $90.3 \pm 3.7$ & $108.1 \pm 7.6$ \\
\hline
\end{tabular}

$\mathrm{DCM}=$ Dichloromethane; $\mathrm{n}=4$.

Table 10: Recoveries of pyrethroids and internal standard at three fortification level.

\begin{tabular}{|l|l|l|l|}
\hline \multicolumn{4}{|l|}{ Average recovery (\%) \pm S.D. } \\
\hline $\begin{array}{l}\text { Pyrethroid \& } \\
\text { Standard }\end{array}$ & Fish & Soil & \\
\hline $10 \mathrm{ppb}$ fortification level & \multicolumn{3}{l|}{} \\
\hline Permethrin cis & $104.5 \pm 5.9$ & $96.9 \pm 4.9$ & $91.9 \pm 5.1$ \\
\hline Permethrin trans & $97.7 \pm 4.8$ & $94.1 \pm 4.2$ & $97.6 \pm 12$ \\
\hline Fenvalerate cis & $108.5 \pm 2.7$ & $92.3 \pm 9.8$ & $104.7 \pm 5.4$ \\
\hline Fenvalerate trans & $102.9 \pm 11$ & $93.9 \pm 7.8$ & $102.8 \pm 5.3$ \\
\hline Cyfluthrin & $100.9 \pm 7.5$ & $96.8 \pm 8.1$ & $101.4 \pm 4.6$ \\
\hline Cypermethrin & $86.9 \pm 1.6$ & $89.4 \pm 10.2$ & $102.2 \pm 4.8$ \\
\hline Deltamethrin & $88.1 \pm 2.7$ & $82.6 \pm 6.3$ & $108 \pm 4.4$ \\
\hline Mirex, standard & $97.4 \pm 4.6$ & $96.6 \pm 6.2$ & $112.8 \pm 8.2$ \\
\hline
\end{tabular}

$50 \mathrm{ppb}$ fortification level

\begin{tabular}{|l|l|l|l|}
\hline Permethrin cis & $108.7 \pm 12$ & $98.9 \pm 6.4$ & $91.4 \pm 5.8$ \\
\hline Permethrin trans & $80.5 \pm 6.3$ & $93.2 \pm 7.2$ & $98.7 \pm 6.6$ \\
\hline Fenvalerate cis & $92.8 \pm 4.1$ & $88.4 \pm 3.9$ & $89.8 \pm 7.1$ \\
\hline Fenvalerate trans & $86.1 \pm 4.6$ & $91.3 \pm 8.1$ & $91.6 \pm 8.1$ \\
\hline Cyfluthrin & $117.7 \pm 2.5$ & $100.5 \pm 4.5$ & $95.5 \pm 4.6$ \\
\hline Cypermethrin & $106.3 \pm 3.2$ & $98.8 \pm 7.7$ & $85.0 \pm 7.8$ \\
\hline Deltamethrin & $115 \pm 7.1$ & $81.7 \pm 4.2$ & $92.6 \pm 5.8$ \\
\hline Mirex, standard & $108.3 \pm 2.1$ & $101.2 \pm 9.1$ & $98.7 \pm 5.8$ \\
\hline
\end{tabular}

$100 \mathrm{ppb}$ fortification level

\begin{tabular}{|l|l|l|l|}
\hline Permethrin cis & $114.5 \pm 2.1$ & $92.7 \pm 11.9$ & $98.1 \pm 11.6$ \\
\hline Permethrin trans & $84.5 \pm 2.8$ & $98.6 \pm 10.9$ & $107.9 \pm 11.2$ \\
\hline Fenvalerate cis & $100.4 \pm 3.7$ & $98.4 \pm 2.4$ & $94.5 \pm 10$ \\
\hline Fenvalerate trans & $98.3 \pm 6.8$ & $94.6 \pm 4.6$ & $80.6 \pm 5.6$ \\
\hline Cyfluthrin & $86.6 \pm 6.9$ & $102 \pm 10.1$ & $87.6 \pm 8.9$ \\
\hline Cypermethrin & $86.6 \pm 5.7$ & $108.2 \pm 2.6$ & $98.5 \pm 8.5$ \\
\hline Deltamethrin & $96.9 \pm 4.5$ & $84.8 \pm 6.3$ & $84.3 \pm 8.2$ \\
\hline Mirex, standard & $84.8 \pm 5.1$ & $98.8 \pm 4.4$ & $100.6 \pm 6.2$ \\
\hline
\end{tabular}

were extracted with hexane-dichloromethane by ultrasonication and cleaned up on Florisil (soil and moss) and mixed acid/base alumina (fish) columns prior to determination by $\mathrm{GC} / \mathrm{NICl}-\mathrm{MS}$ in SIM mode. All the pyrethroids were analyzed simultaneously in a single run on a DB5-MS $15 \mathrm{~m}$ capillary column. Recoveries of the pyrethroids from the three matrices at fortification levels of 10,50 and $100 \mu \mathrm{g} / \mathrm{kg}$ ranged from 80 to $117 \%$. Four determinations were made at each concentration level for each matrix. The practical determination limit of the method was in the range 0.5 to $5 \mu \mathrm{g} / \mathrm{kg}$ depending on the compound. This method was also applied to samples obtained from a contaminated ecosystem.

Figure 13 shows the location of the sampling sites in the Meltham Catchment, West Yorkshire, UK. Figure 14 illustrates the scheme for sample preparation for analysis by $\mathrm{GC} / \mathrm{NICl}-$ MS. Tables 9 and Table 10 summarise the recoveries of pyrethroids for different solvent system used and fortification levels. Tables $11 \mathrm{~A}$ and Table $11 \mathrm{~B}$ summarise the levels of permethrin and cyfluthrin, $A$ in sediment and moss from the catchment sites and B in fish for a selected site HHB. Table 12 summarises the levels of the five pyrethroids $(\mu \mathrm{g} / \mathrm{kg})$ in fish samples from the River Calder at selected sites.

An effective analytical method for the simultaneous determination of five synthetic pyrethroid insecticides in soil was developed and method performance data presented [14]. The pyrethroid residues were extracted with hexanedichloromethane in an ultrasonic bath. The extract was cleaned up on a Florisil column prior to determination by GC-NICl-MS in SIM mode. The highest detection sensitivities were achieved in the SIM mode where the instrument was adjusted to collect only a few ions which were indicative for the compound to be searched for, instead of scanning the entire spectrum over the whole mass range. The gain in sensitivity was the result of longer specific sampling times for each of the ions selected. Recovery studies were performed at 10, 50 and $100 \mathrm{ppb}$ fortification levels of each pyrethroid and of the internal standard, mirex, and the percentage recoveries ranged from $81.7 \pm 4.2$ to $108.2 \pm 2.6 \%$. Four determinations were made at each concentration level along with a procedural blank. The quantification limit of the method was in the range of 0.012 to $4.4 \mathrm{ppb}$, depending on the compound. This method was also applied to sediment samples collected from the environment of a River Catchment which was monitored for the presence of target pyrethroids. Figure 15 illustrates the quality of the linearity for the calibration of the concentrations of permethrin, which provides a prime example of the reliability and sensitivity of $\mathrm{GC} / \mathrm{NICl}-\mathrm{MS}$ employed in these studies. Table 13 summarises the performance data for calibration of the pyrethroids and limits of detection (LOD). Table 14 summarises the levels of permethrin (cis and trans) and cyfluthrin in sediments from sites 1 to 7 in the Meltham catchment, West Yorkshire, UK.

An analytical method based on GC combined with NIClMS in SIM mode has been optimized for the simultaneous determination of five synthetic pyrethroid insecticides in water, sediment, moss and fish tissue [22]. The pyrethroids were originally extracted from the environmental matrices by steam distillation extraction (SDE) but this has since been 
Citation: Baugh PJ (2019) A Review of Pyrethroid and Mitin Analysis in Environmental Matrices by Sample Extraction \& Preparation, ELISAs with A Unique Focus on GC/NICl-MS. Current Trends Anal Bioanal Chem 3(1):125-144

Table 11: A) Permethrin levels $(\mu \mathrm{g} / \mathrm{kg}$ ) in sediments and moss from the Meltham Catchment, East Yorkshire, UK; B) Level of permethrin and cyfluthrin in fish samples originating from Site HHB.

\begin{tabular}{|c|c|c|c|c|c|c|c|c|c|}
\hline $11 \mathrm{~A}$ & \multicolumn{2}{|l|}{ Moss } & \multicolumn{2}{|c|}{ Sediment } & 11B & Weight & Permethrin cis & Permethrin trans & Cyfluthrin \\
\hline \multirow{2}{*}{$\begin{array}{l}\text { Sample } \\
\text { site }\end{array}$} & \multicolumn{2}{|c|}{ Permethrin } & \multicolumn{2}{|c|}{ Permethrin } & Sample & (g) & $\left(\mu \mathrm{kg}^{-1}\right)$ & $\left(\mu \mathrm{kg}^{-1}\right)$ & $\left(\mu \mathrm{kg}^{-1}\right)$ \\
\hline & \multirow{2}{*}{$\begin{array}{l}\text { cis } \\
\text { nd }\end{array}$} & \multirow{2}{*}{$\begin{array}{l}\text { trans } \\
\text { nd }\end{array}$} & \multirow{2}{*}{$\begin{array}{l}\text { cis } \\
\text { nd }\end{array}$} & \multirow{2}{*}{\begin{tabular}{|l|} 
trans \\
nd \\
\end{tabular}} & \multicolumn{5}{|l|}{ Site HHB } \\
\hline BD1 & & & & & HHB1 & 11.58 & 27.5 & 25.55 & 44.4 \\
\hline BD2 & 101.1 & 40.08 & 440.3 & 362.87 & HHB2 & 29.6 & 5769.0 & 357.0 & 30.0 \\
\hline BD3 & 606.91 & 228.4 & 421.9 & 271.92 & HHB3 & 40.4 & 1709.0 & 507.0 & 109.7 \\
\hline BR & 602.9 & 208.22 & 112.49 & 89.7 & HHB4 & 41.4 & 577.0 & 858 & 3.3 \\
\hline$H R$ & 6.07 & 1.72 & 13.5 & 7.25 & HHB5 & 49.4 & 55.0 & 22.0 & 2.55 \\
\hline STW & 214.72 & 65.95 & 165.52 & 89.88 & HHB6 & 70.3 & 794.0 & 1.16 & 3.0 \\
\hline $\mathrm{HHB}$ & 210.46 & 133.82 & 247.28 & 161.68 & HHB7 & 100.8 & 334.0 & 172.0 & nd \\
\hline \multicolumn{5}{|c|}{ All concentrations in $\mu \mathrm{g} \mathrm{kg}^{-1}$} & HHB8 & 116.9 & 118.22 & 10.66 & nd \\
\hline
\end{tabular}

$\mathrm{nd}=$ Not detected.

Table 12: Levels of pyrethroids $(\mu \mathrm{g} / \mathrm{kg})$ in fish samples from the River Calder, West Yorkshire (UK).

\begin{tabular}{|l|l|l|l|l|l|l|}
\hline \multicolumn{9}{|l}{ Fish Sample } & \multicolumn{3}{l|}{} \\
\hline Pyrethroid & Calder 1 & Calder 2 & Calder 3 & Calder 4 & Calder 5 & Calder 6 \\
\hline Permethrin cis & 886.9 & 1204.4 & 862.3 & 922.25 & 568.28 & 398.46 \\
\hline Permethrin trans & 108.9 & 130.0 & 157.58 & 281.74 & 474.76 & 100.6 \\
\hline Cyfluthrin & 6.39 & 14.14 & 19.16 & 26.4 & 5.79 & 9.75 \\
\hline Cypermethrin & 12.24 & 32.86 & 45.33 & 63.64 & 3.48 & 29.47 \\
\hline Fenvalerate cis & 4.02 & 2.7 & 2.56 & 2.43 & 1.35 & 1.15 \\
\hline Fenvalerate trans & 0.49 & 5.82 & 4.4 & 4.96 & 2.84 & 2.72 \\
\hline Deltamethrin & 60.04 & 71.86 & 17.08 & 119.3 & 22.9 & 22.23 \\
\hline
\end{tabular}

All concentrations at $\mu \mathrm{g} \mathrm{kg}^{-1}$ level.

Table 13: Regression data and limit of detection of pyrethroids and internal standard.

\begin{tabular}{|l|l|l|l|}
\hline & Regression equation & Correlation coefficient & $10 \times$ LOD \\
\hline Pyrethroid \& Standard & & & Concentration (ppb) \\
\hline Permethrin cis & $y=0.0002 x+0.0003$ & $r^{2}=0.999$ & 0.012 \\
\hline Permethrin trans & $y=0.0021 x-9 \times 10^{-5}$ & $r^{2}=0.996$ & 0.22 \\
\hline Fenvalerate cis & $Y=0.0517 x+0.0237$ & $r^{2}=0.997$ & 4.4 \\
\hline Fenvalerate trans & $Y=0.0117 x+0.02094$ & $r^{2}=0.998$ & 0.85 \\
\hline Cyfluthrin & $Y=0.01344 x-0.0024$ & $r^{2}=0.995$ & 1.4 \\
\hline Cypermethrin & $Y=0.0046 x+0.0351$ & $r^{2}=0.998$ & 0.69 \\
\hline Deltamethrin & $Y=0.0718 x-0.1909$ & $r^{2}=0.997$ & 4.3 \\
\hline Mirex, Standard & $Y=0.02175 x+0.4717$ & $r^{2}=0.998$ & 0.85 \\
\hline
\end{tabular}

superseded by liquid-liquid extraction (LLE) for water samples and ultrasonic extraction (USE) for solid matrices with particular attention for solvent selectivity. Recovery studies were performed on all the environmental matrices for each pyrethroid and the internal standard, mirex. The percentage recoveries ranged from $80.6 \pm 5.6$ to $116.2 \pm 4.3$, where $n=$ 4. The limit of quantitation for the method was determined statistically from the linear calibration curve, giving values in the range 0.01 to $4.4 \mathrm{pg}$ of material introduced into the system depending on the pyrethroid in question. The method was applied to environmental samples collected from a contaminated river ecosystem currently being monitored for the target analytes. The limit of detection (LOD) formulation for calculating the LODs for pyrethroids reviewed and Table 15 summarises the instrumental detection limits for the respective pyrethroids. Table 16 shows the recoveries of two selected pyrethroids, permethrin and cyfluthrin, employing three different extraction techniques. Table 17 summarises the recoveries of the pyrethroids reviewed from water, sediment, moss and fish tissue at realistic fortification levels 


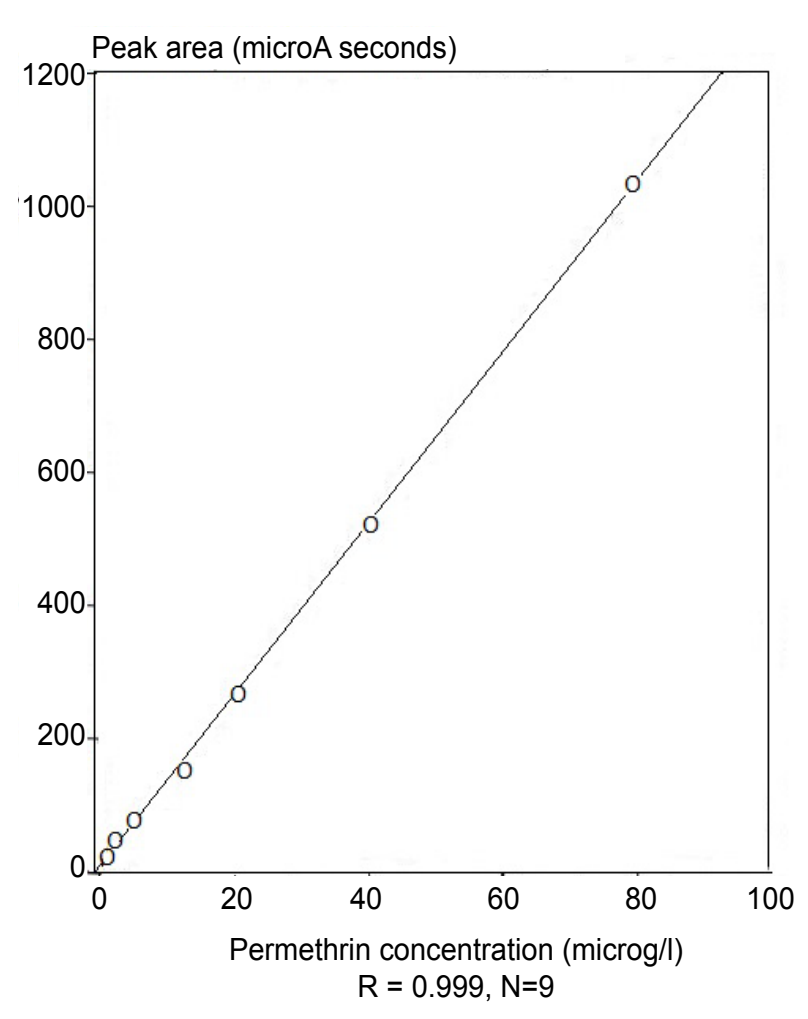

Figure 15: Calibration for permethrin using $\mathrm{GC} / \mathrm{NICl}-\mathrm{MS}$, in concentration range 0 to $80 \mu \mathrm{l}^{-1}$.

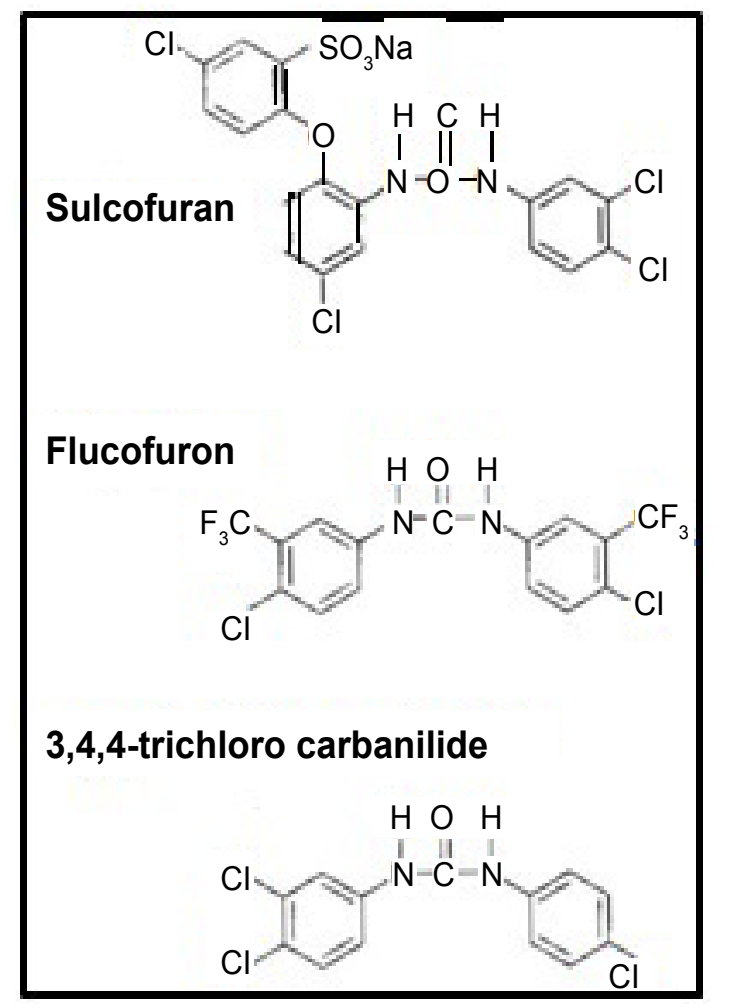

Figure 16: Structures of sulcofuron, flucofuron and trichlorocarbanilide standard.

Table 14: Levels $(\mu \mathrm{g} / \mathrm{kg}$ ) of permethrin and cyfluthrin in sediment from sites 1 to 7 of the Meltham Catchment, West Yorkshire, UK.

\begin{tabular}{|l|l|l|l|l|}
\hline Sampling Site & Permethrin cis & Permethrin trans & Cyfluthrin & Mirex recovery (\%) \\
\hline Site 1 & 42.8 & 19.6 & 1.5 & 75.2 \\
\hline Site 2 & 213.1 & 82.6 & 1.3 & 82.6 \\
\hline Site 3 & 309.5 & 108.7 & 4.6 & 80.2 \\
\hline Site 4 & 67.9 & 24.2 & 5.8 & 86.5 \\
\hline Site 5 & 0.58 & 0.26 & 0.086 & 79.1 \\
\hline Site 6 & 20.1 & 4.6 & 0.45 & 81.4 \\
\hline Site 7 & 132.0 & 22.8 & 0.56 & 87.7 \\
\hline
\end{tabular}

All concentrations at $\mu \mathrm{gg}^{-1}$ level.

Table 15: Instrumental detection limits for the pyrethroids and standard studied.

\begin{tabular}{|l|l|}
\hline Pyrethroid \& Standard & $\begin{array}{l}\text { Instrumental limit of detection } \\
\text { (LOD) } p g\end{array}$ \\
\hline Permethrin cis & $0.001(0.01)$ \\
\hline Permethrin trans & $0.022(0.2)$ \\
\hline Cyfluthrin & $0.14(1.4)$ \\
\hline Cypermethrin & $0.069(0.7)$ \\
\hline Deltamethrin & $0.43(4.3)$ \\
\hline Fenvalerate cis & $0.44(4.4)$ \\
\hline Fenvalerate trans & $0.085(0.9)$ \\
\hline Mirex, standard & $0.085(0.9)$ \\
\hline
\end{tabular}

Values in parenthesis denote $10 \times$ LOD = Limit of quantification. using LLE for water and the preferred technique, USE, for solid matrices.

\section{Applications to other targets: Mitins using liquid chromatography combined with negative-ion electrospray ionization tandem mass spectrom- etry (LC/ESI-MS-MS)}

Flucofuron and sulcofuron, both examples of mitins, were employed as the active ingredients in mothproofing formulations for the protection of textile fabrics by the dyeing industry. Monitoring of their presence in components of the river ecosystem is a regulatory requirement so precise extraction techniques, combined with sensitive detection systems, are required to obtain valid data concerning the levels of target pollutants present. This study $[23,24]$ continued the de- 
Citation: Baugh PJ (2019) A Review of Pyrethroid and Mitin Analysis in Environmental Matrices by Sample Extraction \& Preparation, ELISAs with A Unique Focus on GC/NICl-MS. Current Trends Anal Bioanal Chem 3(1):125-144

Table 16: Recoveries of permethrin, cyfluthrin and mirex standard from water sediment employing different techniques liquid-liquid extraction, LLE, steam distillation extraction, SDE and ultrasonic extraction, USE.

\begin{tabular}{|c|c|c|c|c|}
\hline \multirow[t]{4}{*}{ Pyrethroid and Standard } & \multicolumn{4}{|c|}{ Average recovery (\%) \pm S.D. } \\
\hline & LLE & SDE & & USE \\
\hline & Water & Water & Sediment & Sediment \\
\hline & $10 \mu \mathrm{g} \mathrm{l}^{-1}$ & $10 \mu \mathrm{g} \mathrm{I}^{-1}$ & $100 \mu \mathrm{g} \mathrm{kg}^{-1}$ & $100 \mu \mathrm{g} \mathrm{kg}^{-1}$ \\
\hline Permethrin & $98.5 \pm 3.0(4)$ & $93.9 \pm$ na(2) & $90.9 \pm 14.5(4)$ & $92.7 \pm 11.9(4)$ \\
\hline Cyfluthrin & $97.3 \pm 16.0(4)$ & $72.8 \pm n a(2)$ & $63.9 \pm 12.8(4)$ & $102.0 \pm 10.0(4)$ \\
\hline Mirex & $99.2 \pm 2.4(4)$ & $74.0 \pm \mathrm{na}(2)$ & $82.2 \pm 12.5(4)$ & $98.8 \pm 4.4(4)$ \\
\hline
\end{tabular}

Values in parenthesis denote number of observations, na $=$ Not available.

Table 17: Recovery of pyrethroids from water, sediment, moss and fish tissue at realistic fortification levels.

\begin{tabular}{|l|l|l|l|l|}
\hline \multicolumn{5}{|l|}{ Average recovery (\%) \pm S.D., $\boldsymbol{n}=\mathbf{4}$} \\
\hline Pyrethroid \& standard & Water $^{*}$ & Sediment & Moss & Fish tissue \\
\hline & $10 \mu \mathrm{g} \mathrm{I}^{-1}$ & $100 \mu \mathrm{kg}^{-1}$ & $100 \mu \mathrm{kg}^{-1}$ & $100 \mathrm{\mu g} \mathrm{kg}^{-1}$ \\
\hline Permethrin cis & $98.5 \pm 3.0$ & $92.7 \pm 11.9$ & $98.1 \pm 11.6$ & $114.5 \pm 2.1$ \\
\hline Permethrin trans & $97.6 \pm 8.0$ & $98.6 \pm 10.9$ & $107.9 \pm 11.2$ & $84.5 \pm 2.8$ \\
\hline Cyfluthrin & $97.3 \pm 16.0$ & $102.0 \pm 10.1$ & $87.6 \pm 8.9$ & $86.6 \pm 6.9$ \\
\hline Cypermethrin & $106.7 \pm 6.6$ & $108.2 \pm 2.6$ & $98.5 \pm 8.5$ & $86.6 \pm 5.7$ \\
\hline Deltamethrin & $94.0 \pm 3.9$ & $84.8 \pm 6.3$ & $84.3 \pm 8.2$ & $96.9 \pm 4.5$ \\
\hline Fenvalerate cis & $116.2 \pm 4.3$ & $98.4 \pm 2.4$ & $94.5 \pm 10.0$ & $100.4 \pm 3.7$ \\
\hline Fenvalerate trans & $95.5 \pm 6.6$ & $94.6 \pm 4.6$ & $80.6 \pm 5.6$ & $98.3 \pm 6.8$ \\
\hline Mirex, standard & $99.2 \pm 2.4$ & $98.8 \pm 4.4$ & $100.6 \pm 6.2$ & $84.8 \pm 5.1$ \\
\hline
\end{tabular}

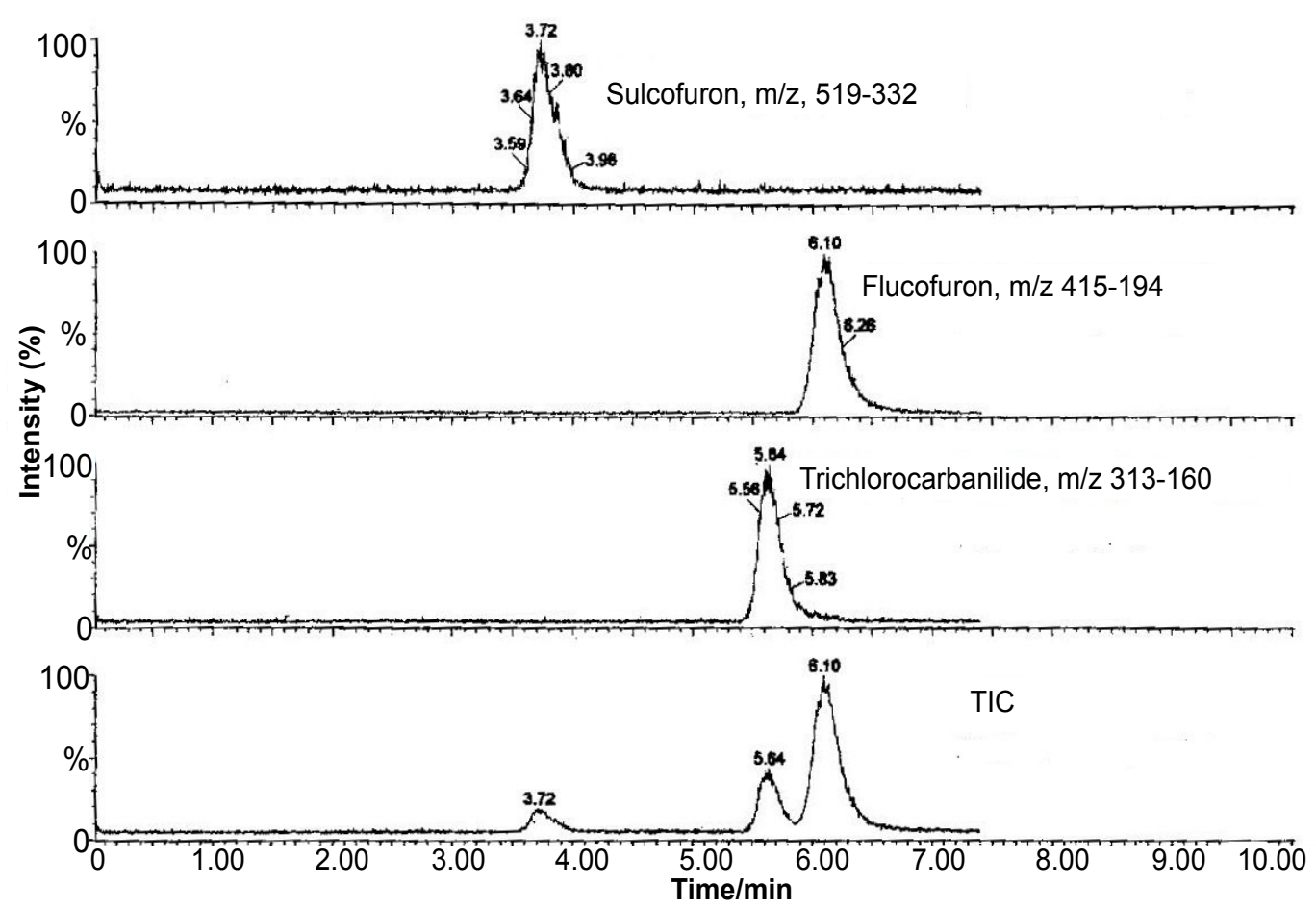

Figure 17: Typical LC/ESI-MS-MS MRM reconstructed ion trace and Total Ion Chromatogram for sulcofuron (transition, $\mathrm{m} / \mathrm{z} 519$-332), flucofuron ( $\mathrm{m} / \mathrm{z} 415$ - 194) and trichlorocarbanilide standard (m/z 313 - 160) in descending order.

velopment LC/ESI-MS-MS operated in the multiple reaction monitoring mode for the determination of these analytes in complex matrices. The paper describes the development of liquid-liquid extraction (LLE) and solid-phase extraction 
(SPE) techniques for the determination of the analytes in environmental river water. The methods employed an internal standard, trichlorocarbanilide (TCC), to check the extraction efficiencies but not to correct environmental data. The extraction efficiencies obtained with LLE were 73.2 $\pm 6.7,112.4$ \pm 8.6 and $96.4 \pm 14.3 \%(n=5)$ compared with $74.3 \pm 8.4,115.9$ \pm 3.1 and $112.7 \pm 4.5 \%(n=4)$ employing SPE for sulcofuron, flucofuron and TCC (100 ng I-1 matrix fortification level), respectively. The SPE results are consistent with those obtained for LLE, although the precision of the SPE method was better than that of the LLE method. These methods were then successfully applied to samples obtained from a contaminated ecosystem. Figure 16 illustrates the structures of the mitins and the standard. Figure 17 shows typical LC/ESI-MS-MS multiple reaction monitoring (MRM) reconstructed ion traces and TIC for sulcofuron, flucofuron and trichlorocarbanilide standard. Figure 18 illustrates the sampling sites in the Meltham catchment of the River Calder, West Yorkshire, UK. Table 18, Table 19 and Table 20 summarise the data obtained for the two mitins investigated.

\section{Sorption - desorption equilibria for pyrethroids in soils}

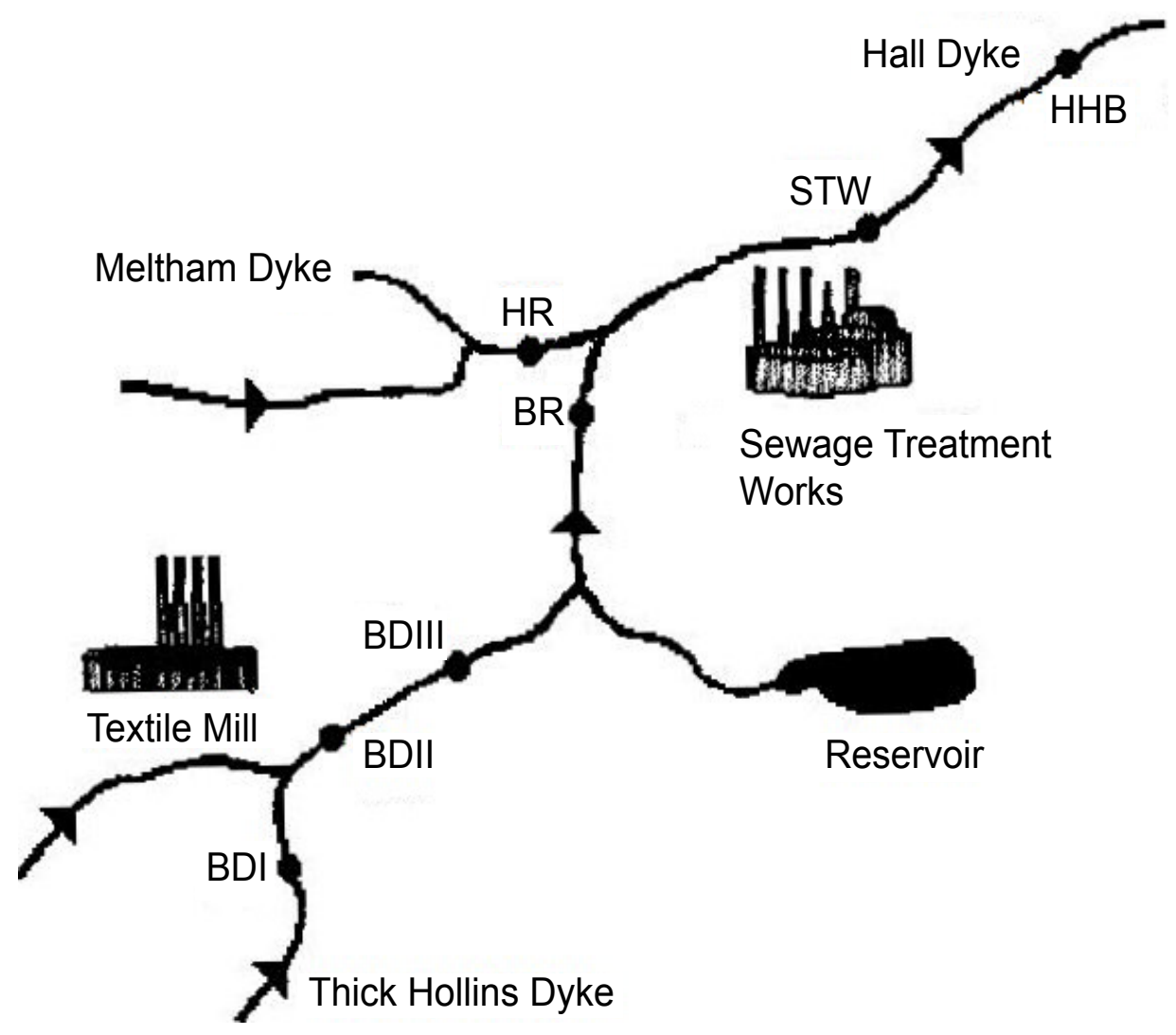

Figure 18: Location of sampling sites in the Meltham Catchment, East Yorkshire, UK.

Table 18: National grid references of the seven sampling sites Meltham a river calder catchment, West Yorkshire, UK, and the concentrations of sulcofuron and flucofuron in river water employing LLE (Oct. 1995) and SPE (June 1997).

\begin{tabular}{|c|c|c|c|c|c|c|}
\hline \multirow[t]{2}{*}{ Sampling Site } & \multirow{2}{*}{$\begin{array}{l}\text { National } \\
\text { Grid reference }\end{array}$} & \multicolumn{2}{|l|}{ LLE } & \multicolumn{3}{|l|}{ SPE } \\
\hline & & Sulcofuron & Flucofuron & Sulcofuron & Flucofuron & TCC recovery (\%) \\
\hline Blank & & N.D. ${ }^{*}$ & N.D. & N.D. & N.D. & 105 \\
\hline BDI & SE 102098 & N.D. & N.D. & N.D. & N.D. & 107 \\
\hline BDII & SE 102100 & N.D. & N.D. & N.D. & N.D. & 100 \\
\hline BDIII & SE 103101 & 4.1 & N.D. & 6.0 & 4.2 & 95 \\
\hline$B R$ & SE 111112 & 2.0 & 1.8. & 6.9 & 4.3 & 102 \\
\hline$H R$ & SE 110113 & 6.7 & 3.8 & 2.7 & 3.8 & 93 \\
\hline STW & SE 114117 & 3.1 & N.D. & N.D. & 4.5 & 99 \\
\hline $\mathrm{HHB}$ & SE 118122 & 8.5 & N.D. & N.D. & 5.7 & 110 \\
\hline
\end{tabular}

${ }^{*}$ N.D $=$ Not detected (less than the LOD). 
Citation: Baugh PJ (2019) A Review of Pyrethroid and Mitin Analysis in Environmental Matrices by Sample Extraction \& Preparation, ELISAs with A Unique Focus on GC/NICl-MS. Current Trends Anal Bioanal Chem 3(1):125-144

Table 19: Dependence of LLE efficiency on water sample pH at 100 $n g \mathrm{l}^{-1}(n=5)$.

\begin{tabular}{|l|l|l|}
\hline \multicolumn{2}{|l|}{} & \multicolumn{2}{l|}{ Recovery $\pm s$ (\%) } \\
\hline Adjusted $\mathrm{pH}$ & Sulcofuron & Flucofuron \\
\hline Blank & N.D. & N.D. \\
\hline 1 & $44.5 \pm 5.8$ & $42.5 \pm 4.5$ \\
\hline 2 & $73.2 \pm 6.7$ & $112.4 \pm 8.6$ \\
\hline 4 & $51.8 \pm 8.2$ & $117.0 \pm 10.1$ \\
\hline 7 & $51.9 \pm 16.9$ & $114.1 \pm 11.6$ \\
\hline
\end{tabular}

"N.D.= Not detected (less than the LOD).

Table 20: SPE efficiencies for sulcofuron and flucofuron and TCC extracted from water using different extraction cartridges and $\mathrm{pH}$ at $1 \mu \mathrm{g} \mathrm{l^{-1 }}$.

\begin{tabular}{|l|l|l|l|l|}
\hline Recovery (\%) & \multicolumn{5}{l|}{} \\
\hline Cartridge & $\mathbf{p H}$ & Sulcofuron & Flucofuron & TCC \\
\hline CH & 2 & 49.7 & 63.6 & N.D. \\
\hline CH & 7 & 74.0 & 129.1 & 83.1 \\
\hline $\mathrm{C}_{8}$ & 2 & 47.3 & 124.6 & N.D. \\
\hline $\mathrm{C}_{18}$ & 7 & 74.3 & 127.3 & 59.3 \\
\hline $\mathrm{C}_{18}$ & 2 & 49.3 & 86.1 & 50.7 \\
\hline $\mathrm{C}_{18}$ & 7 & 70.7 & 113.1 & 86.3 \\
\hline ENV+ & 2 & N.D. & 120.2 & 115.7 \\
\hline ENV+ & 7 & N.D. & 105.8 & 68.5 \\
\hline ENVI-CARB & 2 & N.D. & N.D. & N.D. \\
\hline ENVI-CARB & 7 & N.D. & N.D. & N.D. \\
\hline
\end{tabular}

${ }^{*}$ N.D. $=$ Not detected (less than the LOD).
Several related studies were conducted to establish sorption desorption equilibria for pyrethroids in soils, the first investigating the suitability of binary solvent systems for establishing the recoveries of pyrethroids from soils and the second a study of the sorption - desorption equilibria in soils.

Development of a binary solvent system for analysis of pyrethroids on soil: Ultrasonic extraction was used to develop a suitable binary solvent system for the analysis of synthetic pyrethroid pesticides and mirex on soil [25]. The analysis was carried out by $\mathrm{GC} / \mathrm{NICl}-\mathrm{MS}$ ). In the initial experiments, accurately weighed soil samples were spiked with a mixture of standard solution pyrethroids and mirex and shaken for $24 \mathrm{~h}$ to ensure homogeneity, then extracted with solvent. The extracts were evaporated to dryness before the volumetric internal standard was added.

The binary solvents used in this study were various mixtures of hexane: acetone, hexane: dichloromethane (DCM), isooctane: acetone and isooctane: dichloromethane, representing different classes of polarity. The recoveries of all pyrethroids and mirex were satisfactory over three solvent systems, but results of isooctane: DCM produced low recoveries. The average recovery increased with the extraction time, but the increase was not statistically significant. A 30-min optimum extraction was deemed sufficient for recovering pyrethroids from soil. After $30 \mathrm{~min}$, extraction decreased owing to the re-distribution of the analyte on the soil matrix.

Table 21 summarises the percentage recoveries of six pyrethroids using different solvent systems and compositions at $1 \mathrm{mg} \mathrm{l}^{-1}$ concentration level.

Sorption-desorption equilibria for pyrethroids on soils: Sorption-desorption equilibria of six pyrethroids (permethrin,

Table 21: Variation in \% recoveries obtained for pyrethroids with the composition of four solvent systems using GC/NICl-MS.

\begin{tabular}{|c|c|c|c|c|c|c|c|c|}
\hline \multirow[t]{2}{*}{ Solvent } & \multirow[t]{2}{*}{ Composition } & \multirow[t]{2}{*}{$\mathbf{P}^{*}$} & \multicolumn{6}{|l|}{ Recovery, \% } \\
\hline & & & Permethrin & Cyfluthrin & Cypermethrin & Fenvalerate & Deltamethrin & Mirex \\
\hline \multirow[t]{4}{*}{ Hexane: Acetone } & 85: 15 & 0.81 & 62.63 & 99.30 & 117.97 & 96.21 & 83.9 & 66.61 \\
\hline & $65: 35$ & 1.89 & 59.25 & 86.37 & 79.69 & 64.32 & 115.42 & 65.33 \\
\hline & $35: 65$ & 3.51 & 72.60 & 84.94 & 78.95 & 95.48 & 103.93 & 63.83 \\
\hline & 15: 85 & 4.59 & 73.71 & 81.88 & 81.42 & 74.94 & 106.46 & 64.20 \\
\hline \multirow[t]{4}{*}{ Hexane: DCM } & 85: 15 & 0.51 & 56.65 & 36.51 & 38.80 & 31.62 & 42.30 & 70.19 \\
\hline & $65: 35$ & 1.19 & 78.10 & 90.22 & 84.44 & 90.10 & 94.00 & 75.71 \\
\hline & 35: 65 & 2.21 & 91.18 & 87.84 & 78.91 & 87.22 & 103.24 & 97.00 \\
\hline & 15: 85 & 2.89 & 92.92 & 93.51 & 88.20 & 93.44 & 79.00 & 79.27 \\
\hline \multirow[t]{4}{*}{ Isooctane: Acetone } & $85: 15$ & 0.47 & 74.00 & 85.96 & 76.38 & 80.46 & 95.55 & 84.24 \\
\hline & 65: 35 & 1.63 & 72.55 & 88.73 & 105.72 & 83.53 & 90.22 & 92.51 \\
\hline & $35: 65$ & 3.37 & 90.67 & 97.98 & 58.00 & 86.92 & 76.52 & 94.70 \\
\hline & 15: 85 & 4.53 & 70.46 & 78.63 & 46.85 & 68.16 & 57.64 & 87.62 \\
\hline \multirow[t]{4}{*}{ Isooctane: DCM } & 85: 15 & 0.17 & 74.62 & 42.84 & 55.43 & 66.33 & 39.63 & 69.57 \\
\hline & $65: 35$ & 0.93 & 77.27 & 55.56 & 58.14 & 71.28 & 52.18 & 73.19 \\
\hline & 35: 65 & 2.07 & 74.50 & 61.00 & 74.40 & 92.53 & 56.84 & 72.63 \\
\hline & $15: 85$ & 2.83 & 70.78 & 59.94 & 65.11 & 82.74 & 60.41 & 73.74 \\
\hline
\end{tabular}

${ }^{*}$ RSD 3.9\% $(n=3)$. 
Citation: Baugh PJ (2019) A Review of Pyrethroid and Mitin Analysis in Environmental Matrices by Sample Extraction \& Preparation, ELISAs with A Unique Focus on GC/NICl-MS. Current Trends Anal Bioanal Chem 3(1):125-144

Table 22: Freundlich parameters for pyrethroids and mirex in soil sample studied (organic content $2.1 \%$ ). Note: $\lambda$ - cyhalothrin was also studied in this paper, see above structure.

\begin{tabular}{|l|l|l|l|}
\hline Pyrethroid and Standard & Slope, $\mathbf{1 / n}$ & $\mathbf{n}$ & $\mathbf{k}$ \\
\hline Cyfluthrin & 1.1014 & 0.906 & 1.021 \\
\hline$\lambda$-cyhalothrin & 1.1000 & 0.909 & 7.603 \\
\hline Cypermethrin & 0.9965 & 1.004 & 5.233 \\
\hline Deltamethrin & 1.1000 & 0.909 & 2.443 \\
\hline Fenvalerate & 0.9561 & 1.046 & 13.105 \\
\hline Permethrin & 0.9927 & 1.007 & 1.874 \\
\hline Mirex, Standard & 1.1018 & 0.907 & 12.705 \\
\hline
\end{tabular}

$\mathrm{RSD} \pm 2.5-4.6, \mathrm{n}=3$.

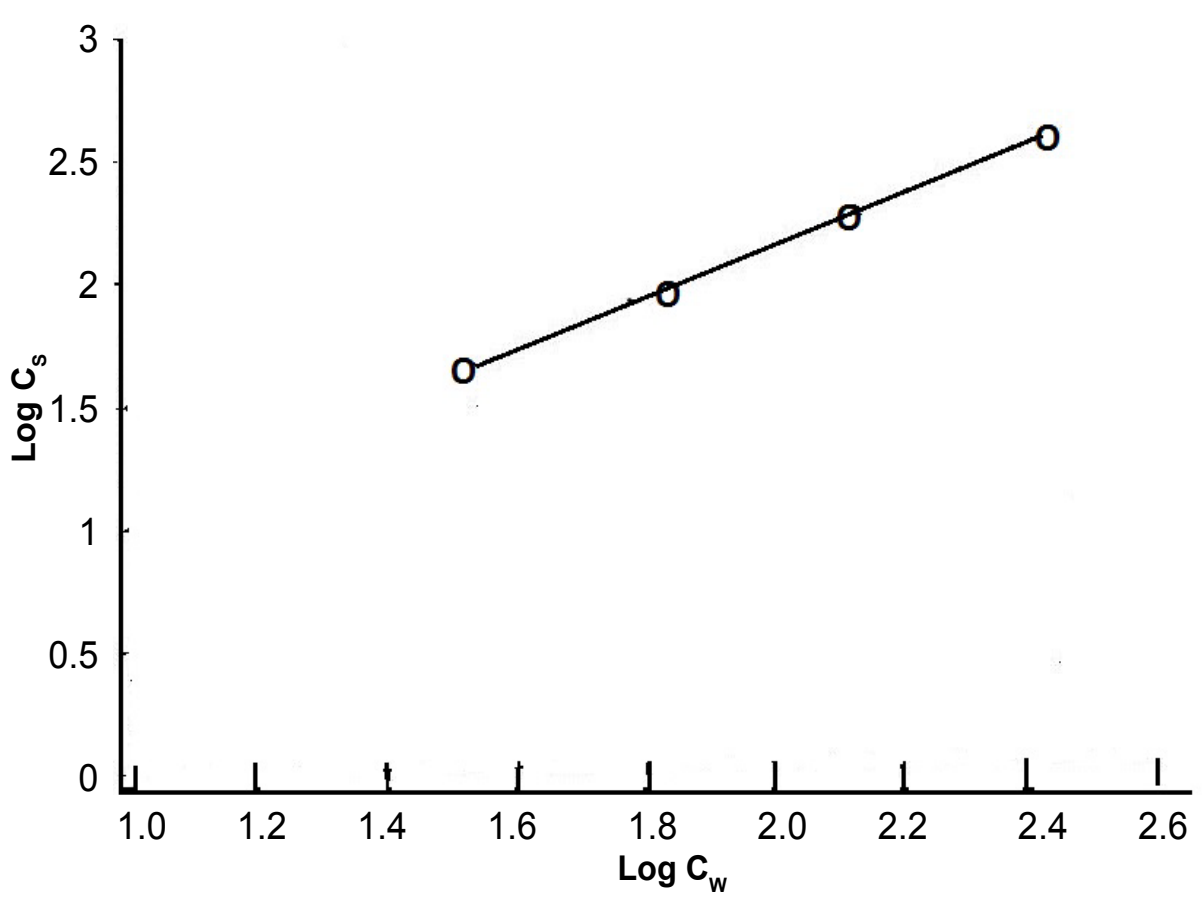

Figure 19: Sorption isotherm curve for cyfluthrin.

cyfluthrin, cypermethrin, $\lambda$-cyhalothrin, deltamethrin and fenvalerate) and mirex were determined in soils possessing a range of organic content (1.15-2.46\%) [26]. Solutions (in deionized water, $\mathrm{pH}$ 6.5-7.4) of the samples were shaken using a mechanical shaker for $24 \mathrm{~h}$. The suspensions were centrifuged and aliquots of clear supernatant were passed through a C-18 column (SPE extraction). The eluates were concentrated to dryness before a volumetric standard was added. The analytes were determined by GC/NICl-MS either in SIM or scan (SCN) mode. Sorption isotherm parameters ( $n$ and $k$ ) were calculated according to the Freundlich equation. The values of $n$ are around unity. Permethrin and cyfluthrin were the least sorbed pyrethroids, $k<2$, mirex and fenvalerate the most. The effect of the $\mathrm{pH}$ on sorption was examined also (at $\mathrm{pH}$ values 2, 4, 6 and 9). Sorption behaviour on different soils and silica was also examined. Desorption studies were conducted on the same pyrethroid solutions. After sorption, the supernatant was replaced with a similar volume of deionized water. Desorption was achieved by removing all the superna- tant from the centrifuged samples and then replacing it with deionized water. This equilibration process was repeated five times. Each time the suspension was centrifuged, concentrated and analyzed using GC/NICl-MS. The residual amount of pyrethroid on the soil was calculated as the difference between the initial amount and the desorbed amount (mass balance) (Table 22).

Figure 19 shows a typical sorption isotherm curve for cyfluthrin as an example and Table 22 summarises the Freundlich parameters for the six pyrethroids investigated using the formula:

$$
C_{S}=\mathrm{k} \cdot C_{w}^{1 / n} \cdot \log C_{S}=1 / \mathrm{n} \cdot \log C_{w}+\log k
$$

where $\mathrm{C}_{\mathrm{s}}\left(\mathrm{mg} \mathrm{kg}^{-1}\right)$ is the total chemical concentration associated with the sorbent, $\mathrm{C}_{\mathrm{w}}\left(\mathrm{mg} \mathrm{l}^{-1}\right)$ is the total chemical concentration in solution and $k$ is adsorption coefficient The log form is used to plot the sorption isotherm curve, as illustrated in Figure 19. 
Citation: Baugh PJ (2019) A Review of Pyrethroid and Mitin Analysis in Environmental Matrices by Sample Extraction \& Preparation, ELISAs with A Unique Focus on GC/NICl-MS. Current Trends Anal Bioanal Chem 3(1):125-144

\section{GC/NICI-MS using stable isotope analogue stan- dards as reference}

Unreported studies at Salford in the 1990s focused on the synthesis of $d_{6}$ permethrin substituted at the cyclopropane exocyclic methyl groups, i.e., $\mathrm{CD}_{3} \cdot \mathrm{CD}_{3}$. The shift of 6 mass units from the parent facilitates the monitoring of the analogue and target analyte at low mass resolution using SIM. Preliminary results on environmental samples from water course sources provided information about the enhancement in the determination and quantisation of permethrin [27].

The following more recent paper has relevance to the above unreported work and is included here for this purpose.

Koch, Clark and Tessier [28] have utilized stable isotope analogues for analysing pyrethroids in environmental samples from effluent waters from wastewater treatment facilities to increase the accuracy of determination of the target pyrethroids. Stable isotope internal standards are useful in correcting for matrix effects and instrumental variability when environmental samples such as wastewaters and biosolids are analyzed by mass spectral methods. This paper reports the use of deuterium-labeled analogues of eight pyrethroid insecticides to improve accuracy for the analysis of environmental samples by negative chemical ionization gas chromatography with mass spectrometric detection ( $\mathrm{NCl}-$ GC-MS). Data for the analysis of effluent water from wastewater treatment facilities are presented which demonstrate that the method is rugged and capable of achieving limits of quantification (LOQs) as low as $0.5 \mathrm{ng} / \mathrm{L}$ (ppt), with individual recoveries within the range of $81-94 \%$ for those compounds with minimal control background concentrations. In addition, an alternate use of the deuterium-labeled standards is proposed for the determination of method recoveries at low levels that would normally have been precluded due to background pyrethroid levels present in environmental samples being used for control fortifications.

\section{Summary of Recent Advances in the Appli- cations of GC/NICl-MS to Environmental Sys- tems}

In period 2003 to date a number of studies have reported on the applications of $\mathrm{GC} / \mathrm{NICl}-\mathrm{MS}$ to the determination of pyrethroids in environmental and biological matrices including plasma.

For example, Ramesh and Ravi [15] have analysed pyrethroid insecticides in whole blood and serum. A new rapid and sensitive analytical method using NICl-GC-MS in SIM mode has been developed for the determination of residues of different synthetic pyrethroid insecticides, allethrin, bifenthrin, cypermethrin, cyphonothrin, cyfluthrin, $\lambda$-cyhalothrin, deltamethrin, fenvalerate, fenpropathrin, permethrin, prallethrin, and trans-fluthrin, in whole blood. The residues of pyrethroid molecules were extracted from the whole blood using a hexane and acetone $(8: 2, \mathrm{v} / \mathrm{v})$ solvent mixture without separating the serum. The method was found sensitive to detect the residues of pyrethroids up to the level $0.2 \mathrm{pg} /$ $\mathrm{mL}$. Experiments conducted with the whole blood samples at the fortification level $1-100 \mathrm{pg} / \mathrm{mL}$ showed $9-103 \%$ recovery, whereas blood serum samples collected after the fortification of pyrethroids in whole blood showed $36-54 \%$ recovery. Recovery experiments conducted by direct fortification of pyrethroids in blood serum samples showed $96-108 \%$. The applications of the analytical method were tested by analyzing 73 human blood samples collected from the population exposed continuously to different pyrethroid-based formulations. None of the blood samples showed residues of pyrethroids. The results were also confirmed by the detection of the appropriate amounts in a number of these samples, which had subsequently been spiked with known quantity of pyrethroids.

Koch and Tessier [28], as already described in section 2.7, have employed stable isotope analogues to increase the confidence in the determination of pyrethroids in effluent waters.

Barcelo, et al. [29] have used GC/MS-MS to analyse twelve pyrethroid insecticides in environmental and food samples. First, a comparison of two different ionization modes, EI and $\mathrm{NICl}$, was carried out using MS and MS-MS. NICI-MS-MS provided the best results in terms of selectivity and sensitivity giving very low detection limits of 0.11 to $450 \mathrm{fg}$ injected. The reliability of the method was confirmed through the evaluation of quality parameters such as accuracy (70-100\%), and repeatability and reproducibility, with coefficients of variation below $15 \%$ and $10 \%$, respectively. The applicability of the GC/MS-MS method to real samples and influence of matrix effects were evaluated through the analysis of spiked water, sediment and milk at $0.25 \mathrm{ng} \mathrm{L}^{-1}, 5 \mathrm{ng} \mathrm{g}^{-1}$ dry weight (dw) and $25 \mathrm{ng} \mathrm{g}^{-1}(\mathrm{dw})$, respectively, of each pyrethroid insecticide considered. Using GC/NICl-MS-MS, matrix spectral interferences were minimized providing method limits of detection (MLODs) of 0.05-2.59 $\mathrm{ng} \mathrm{L}^{-1}, 0.10-87.7 \mathrm{pg} \mathrm{g}^{-1} \mathrm{dw}$, 2.29-1071 $\mathrm{pg} \mathrm{g}^{-1}$ lipid weight (Iw) for water, sediment and milk, respectively. To the best of knowledge considered, the MLOD values found in this study were better than those reported in previous studies; in particular for sediment and food samples, the values were one order of magnitude lower.

\section{Recent Results on the Application of ELISA to Determine Pyrethroids in Bednets}

A very recent report [30] has appeared on the assessment of analytical methods for the determination of pyrethroids in bednets of which an outline is described below.

The objective was to present and evaluate simple, cost-effective tests to determine the amount of insecticide on treated materials. Methods were developed and evaluated a competitive immunoassay on two different platforms: a label-free impedimetric biosensor (EIS biosensor) and a lateral flow. Both approaches were validated by gas chromatography (GC) and ELISA, gold standards for analytical methods and immune assays, respectively. Finally, commercially available pyrethroid-treated ITN samples were analysed. Different extraction methods were evaluated. results Insecticide extraction by direct infusion of the ITN samples with 
Citation: Baugh PJ (2019) A Review of Pyrethroid and Mitin Analysis in Environmental Matrices by Sample Extraction \& Preparation, ELISAs with A Unique Focus on GC/NICl-MS. Current Trends Anal Bioanal Chem 3(1):125-144

dichloromethane and dioxane showed recovery efficiencies around $100 \%$ for insecticide-coated bednets, and $>70 \%$ for insecticide-incorporated bednets. These results were comparable to those obtained with standard sonication methods. The competitive immunoassay characterisation with ELISA presented a dynamic range between $12 \mathrm{nM}$ and $1.5 \mathrm{IM}$ (coefficient of variation (CV) below 5\%), with an IC50 at $138 \mathrm{nM}$, and a limit of detection (LOD) of $3.2 \mathrm{nM}$. EIS biosensor had a linear range between $1.7 \mathrm{nM}$ and61 nM (CV around 14\%), with an IC50 at $10.4 \mathrm{nM}$, and a LOD of $0.6 \mathrm{nM}$. Finally, the lateral flow approach showed a dynamic range between 150 $\mathrm{nM}$ and $1.5 \mathrm{IM}$, an IC50 at $505 \mathrm{nM}$ and a LOD of67 nM. It was ELISA can replace chromatography as an accurate laboratory technique to determine insecticide concentration in bednets. The lateral flow approach developed can be used to estimate ITN insecticide concentration in the field. This new technology, coupled to the new extraction methods, should provide reliable guidelines for ITN use and replacement in the field.

\section{General Reference of Relevance to the Analy- sis of Pyrethroids}

A very recent reference of general relevance to the trace analysis of pyrethroids has appeared on line as a review by Albaseer [31] of comments on the current state of the art in sampling and chromatographic methods. This review is worthy of inclusion because of where the author is located, in a university institution, in war torn Yemen.

\section{Conclusions}

Although not widely employed, GC/NICl-MS, in correlation studies with ELISAs, has been uniquely applied to determine pyrethroid residues in environmental systems from the 1990 s to early 2000s. In addition, the employment of LC/ ESI-MS-MS in the quantification and monitoring of selected mitins in water courses is an instrumental technique, which is shown to be of high quality in this review. The update of papers reported indicates that this premise remains and it can be concluded that the earlier research is still of current relevance.

\section{Acknowledgements}

The author wishes to acknowledge the contributions of the research students, research assistants and members of staff in the Departments of Biological Sciences and Chemistry at the time the research work was undertaken, whose names appear in the resulting publications, cited in the references following, including Dr. Dai Davies (retired, The Dept. of Biological Sciences), Dr. Graham Bonwick (Dept of Biological Sciences/University of Chester/Fera Science), Professor Chris Smith (North East Wales Institute/Cortecs/MMU), Dr. Peter Hancock (Dept. of Chemistry/Waters Corporation), Dr. Puziah Abdul Latif (Dept. of Chemistry/Malaysia), Dr. Mohammed Yasin (Dept. of Chemistry/Astrazeneca/Iraq)), Dr. Mohammed Adam (Dept. of Chemistry/Sudan), Dr. C Sun (Dept. of Chemistry/Nanjing-China), Dr. Simon White (Dept. of Chemistry/Waters Corporation), David Catlow (Astrazeneca).

\section{References}

1. Guide to Codex recommendations concerning pesticide residues. Pt. 5 (1984) Recommended method of sampling for the determination of pesticide residues.

2. (2014) Joint FAO/WHO meeting on pesticide residues - World health organization.

3. http://www.fao.org/fao-who-codexalimentarius/codex-texts/ $\mathrm{dbs} /$ pestres/pesticides/en/

4. (2015) Environment quality standards.

5. Bolygo E, Zakar F (1983) Gas-liquid chromatographic screening method for six synthetic pyrethroid insecticides. J Assoc Off Anal Chem 66: 1013-1017.

6. Jenkins DW, Hensens A, Lloyd J, et al. (2013) Development and validation of a 'universal' HPLC method for pyrethroid quantification in long-lasting insecticidal mosquito nets for malaria control and prevention. Trop Med Int Health 18: 2-11.

7. Standing Committee of Analysts (1992) Chlorophenylid, flucofuron and sulcofuron in water (tentative methods), in methods for the examination of waters and associated materials, HM Stationary Office, London.

8. (2000) Selected water quality standards

9. Tadeo J L (2019) Analysis of pesticides in food and environmental samples. ( $\left.2^{\text {nd }} e d n\right)$, CRC Press, pp 423.

10. Mothproofing Agents and Water Course Management (1996) R\&D Project Record, CEnvironment Publication code: NE-12/9625-A-AXAP.

11. Bonwick GA, Putman M, Baugh PJ, et al. (1994) Immunoassay development for permethrin residues. Food \& Agricultural Immunology 6: 341-356.

12. Bonwick GA, Cresswell JE, Tyreman AL, et al. (1996) Production of murine monoclonal antibodies against sulcofuron and flucofuron by in vitro immunization. J Immunological Methods 196: 163-173.

13. Yasin M, Baugh PJ, Hancock P, et al. (1995) Synthetic pyrethroid insecticides analysis by gas chromatography operated in negative-ion chemical ionization mode in soil, moss and fish tissue. Rapid Commun Mass Spectrom 9: 1411-1417.

14. Yasin M, Baugh PJ, Bonwick GA, et al. (1996) Analytical method development for the determination of synthetic pyrethroid insecticides in soil by gas chromatography - mass spectrometry operated in negative-ion chemical ionisation mode. J Chromatogr A 754: 235-243.

15. Ramesh A, Elumalai Ravi PE (2004) Negative ion chemical ionization-gas chromatographic-mass spectrometric determination of residues of different pyrethroid insecticides in whole blood. J Anal Toxicol 28: 660-666.

16. Bonwick GA, Abdul-Latif P, Sun C, et al. (1994) Comparison of chemical methods and immunoassay for the detection of pesticide residues in various matrices. Food \& Agricultural Immunology 6: 267-276.

17. Bonwick GA, Yasin M, Hancock P, et al. (1996) Synthetic pyrethroid insecticides in fish: Analysis by gas chromatography mass spectrometry operated in negative ion chemical ionization mode and ELISA. Food \& Agricultural Immunology 8: 185-194.

18. Ali MA, P Baugh PJ, Davies DH, et al. (2004) Correlation Studies between Elisa and GC-MS for the Analysis of pesticide residues 
in mosquito net materials. Poster presented at the 2 nd National Meeting on Environmental Mass Spectrometry, April 01, University college chester.

19. Ali MA, Baugh PJ, Davies DH, et al. (2004) Correlation studies between Elisa and GC-MS for the analysis of pesticide residues in mosquito net materials. Poster presented at the 28th Annual BMSS meeting, University of Derby, September 5-8.

20. Ali M A (2003) PhD Thesis, University of Salford, UK.

21. Bonwick GA, Sun C, Abdul-Latif P, et al. (1995) Determination of permethrin and cyfluthrin in water and sediment by gas chromatography - mass spectrometry operated in the negative ion chemical ionisation mode. J Chromatogr 707: 293-302.

22. Hancock PM, M Yasin M, Baugh PJG, et al. (1997) Optimization of high quality analytical methods for the monitoring of pyrethroid mothproofing agents by gas chromatography - mass spectrometry operated in negative-ion chemical ionization mode. Intern J Environ Anal Chem 67: 81-95.

23. Hancock PM, White SJG, Catlow DA, et al. (1997) Determination of the Mitins, Sulcofuron and Flucofuron, using liquid chromatography combined with negative-ion electrospray ionization mass spectrometry. Rapid Commun Mass Spectrom 38: 195-200.

24. Hancock PM, Walsh M, White SJG, et al. (1998) Extraction and determination of the Mitins sulcofuron and flucofuron from environment river water. Analyst 123: 1669-1974.
25. Ali MA, Baugh P J (2003) Pyrethroid soil extraction, properties of mixed solvents and time profiles using GC/MS-NICl. Int J Environ Anal Chem 83: 909-922.

26. MA Ali MA, Baugh PJ (2003) Sorption-desorption studies of six pyrethroids and Mirex on soils using GC/MS-NICl. Int J Environ Anal Chem 83: 923-933.

27. Hancock PM (1998) PhD Thesis, Undergraduate Dissertation, University of Salford, McGill C, UK.

28. Koch del A, Clark K, Tessier DM (2013) Quantification of pyrethroids in environmental samples using NCl-GC-MS with stable isotope analogue standards 61: 2330-2339.

29. Feo M L, Eljarrat E, Barcelo D (2011) Performance of gas chromatography/tandem mass spectrometry in the analysis of pyrethroid insecticides in environmental and food samples. Rapid Communications in Mass Spectrometry 25: 869-876.

30. Castellarnau M, Ramon-Azcon J, Gonzalez-Quinteiro $Y$, et al. (2017) Assessment of analytical methods to determine pyrethroids content of bednets. Tropical Medicine and International Health 22: 41-51.

31. Albaseer S (2018) Trace analysis of synthetic pyrethroids: Comments on the current state of the art in sampling and chromatographic methods. Research Journal of Chemical Sciences 8: 1322. 